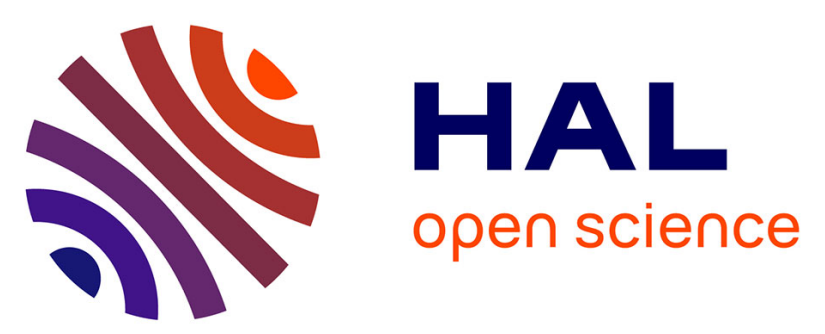

\title{
Formation of Heteropolynuclear Lanthanide Complexes Using Macrocyclic Phosphonated Cyclam-Based Ligands
}

Richard Knighton, Lohona Soro, Thibault Troadec, Valérie Mazan, Aline

Nonat, Mourad Elhabiri, Nathalie Saffon-Merceron, Saifou Djenad, Raphäl

Tripier, Loic J. Charbonniere

\section{To cite this version:}

Richard Knighton, Lohona Soro, Thibault Troadec, Valérie Mazan, Aline Nonat, et al.. Formation of Heteropolynuclear Lanthanide Complexes Using Macrocyclic Phosphonated Cyclam-Based Ligands. Inorganic Chemistry, 2020, 59 (14), pp.10311-10327. 10.1021/acs.inorgchem.0c01456 . hal-02903590

\section{HAL Id: hal-02903590 \\ https://hal.univ-brest.fr/hal-02903590}

Submitted on 15 Sep 2020

HAL is a multi-disciplinary open access archive for the deposit and dissemination of scientific research documents, whether they are published or not. The documents may come from teaching and research institutions in France or abroad, or from public or private research centers.
L'archive ouverte pluridisciplinaire HAL, est destinée au dépôt et à la diffusion de documents scientifiques de niveau recherche, publiés ou non, émanant des établissements d'enseignement et de recherche français ou étrangers, des laboratoires publics ou privés. 


\title{
Formation of Heteropolynuclear Lanthanide
}

\section{Complexes Using Macrocyclic Phosphonated}

\section{Cyclam-Based Ligands}

Richard C. Knighton, ${ }^{\dagger, t} *$ Lohona K. Soro, ${ }^{*}$ Thibault Troadec, ${ }^{\dagger}$ Valerie Mazan,, Aline M. Nonat,,$*$ Mourad Elhabiri, ${ }^{\S}$ Nathalie Saffon-Merceron," Saifou Djenad, ${ }^{\star}$ Raphaël Tripier, ${ }^{\dagger}$ and Loïc J. Charbonnière, $* *$

$\dagger$ Univ. Brest, UMR CNRS 6521 CEMCA, 6 Avenue Victor le Gorgeu, 29200 Brest, France. $\$$ Equipe de Synthèse Pour l'Analyse (SynPA), Institut Pluridisciplinaire Hubert Curien (IPHC), UMR 7178 CNRS/Université de Strasbourg, ECPM, Bâtiment R1N0, 25, rue Becquerel, 67087 Strasbourg Cedex 2, France. E-mails: knighton@unistra.fr; 1.charbonn@unistra.fr § Equipe Chimie Bioorganique et Médicinale, Laboratoire d'Innovation Moléculaire et Applications (LIMA), UMR7042 CNRS-Unistra-UHA, ECPM, 25, rue Becquerel, 67087 Strasbourg Cedex 2, France. ॥ Institut de Chimie de Toulouse (FR 2599), 118 route de Narbonne, 31062 Toulouse Cedex 9, France.

KEYWORDS. Cyclam, phosphonate, heteropolynuclear, lanthanide, luminescence

\begin{abstract}
Ligands $\mathbf{L}_{1}$ and $\mathbf{L}_{2}$, respectively based on a cyclam and a cross-bridged cyclam scaffold functionalised at N1 and N8 by 6-phosphonic-2-methylene pyridyl groups are described. While
\end{abstract}


complexation of lanthanide ( $\mathrm{Ln}$ ) cations with $\mathbf{L}_{2}$ was not possible, a family of complexes has been prepared with $\mathbf{L}_{1}$, of the general formulae $\left[\mathrm{LnL}_{1} \mathrm{D}_{2}\right] \mathrm{Cl}\left(\mathrm{Ln}^{3+}=\mathrm{Lu}, \mathrm{Tb}, \mathrm{Yb}\right)$ or $\left[\mathrm{LnL}_{1} \mathrm{D}\right]\left(\mathrm{Ln}^{3+}=\right.$ $\mathrm{Eu}$ ). The solution, structural, potentiometric and photophysical data for these novel ligands and their complexes have been investigated, including solid-state study by X-ray diffraction $\left(\mathbf{L}_{1}, \mathbf{L}_{2}\right.$ and $\left.\left[\mathrm{Eu} \mathbf{L} \mathbf{H}^{\mathrm{H}}\right]\right),{ }^{1} \mathrm{H}$ NMR complexation investigations $\left(\mathrm{Lu}^{3+}\right)$ as well as $\mathrm{UV}-\mathrm{Vis}$ absorption and luminescence spectroscopy in water and $\mathrm{D}_{2} \mathrm{O}(\mathrm{pH} \approx 7)$. $\mathbf{L}_{\mathbf{1}}$ forms 1:1 metal-ligand stoichiometric octadentate complexes in solution. Importantly the pyridyl phosphonate functions are capable of simultaneous chelation to the metal centre and of interaction with a second metal centre. ${ }^{1} \mathrm{H}$ NMR $\left(\mathrm{Lu}^{3+}\right)$ and spectrophotometric titrations of the isolated $\left[\mathrm{Tb}_{\mathbf{1}}\right]^{-}$complex by $\mathrm{EuCl}_{3}$ salts demonstrated the formation of high order (hetero)polymetallic species in aqueous solution $\left(\mathrm{H}_{2} \mathrm{O}\right.$, $\mathrm{pH}=7$ ). Global analysis of the luminescence titration experiment points to the formation of $4: 1$, 3:1, and 3:2 [TbL1]:Eu heteropolynuclear assemblies, exhibiting a strong preference to forming $\left[\mathrm{Tb} \mathbf{L}_{1}\right]_{3} \mathrm{Eu}_{2}$ at increased europium concentrations, with energy transfer occurring between the kinetically inert terbium complex and added europium cations.

\section{Introduction}

Lanthanide coordination complexes are a privileged class of luminescent materials, exhibiting several distinctive optical characteristics including long-lived excited states, sharp emission bands which are generally unperturbed by the ligand field, ${ }^{1}$ and the absence of a Stokes' shift. ${ }^{2,3,4}$ These properties are a consequence of the valence electron configuration ([Xe] $\left.4 \mathrm{f}^{\mathrm{n}}, \mathrm{n}=0-14\right)$, involving Laporte forbidden $f-f$ transitions between heavily shielded $f$-orbitals. The disallowed nature of the electronic transitions comprising absorption and emission gives rise to very low absorption coefficients $\left(1-10 \mathrm{M}^{-1} \mathrm{~cm}^{-1}\right)^{5}$ and long excited state lifetimes ( $\mu$ s to ms regime) $;{ }^{6}$ the former is typically circumvented through the use of a sensitising donor chromophore to populate the 
lanthanide excited state via the antennae effect. ${ }^{7}{ }^{8}$ Consequently, the energy transfer properties of luminescent $f$-metal complexes are a fertile area of research. ${ }^{9,10,11,12,13}$ Indeed their unique hierarchical energy levels render them attractive candidates in this regard, as both donors and acceptors of energy, and it has previously been shown that efficient molecular inter-lanthanide energy transfer occurs in both homonuclear ${ }^{14,15}$ and heteronuclear complexes. ${ }^{16,17,18}$

The synthesis of homopolynuclear lanthanide complexes has been explored for a range of conventional multi-chelating ligands, ${ }^{19,20,21,22}$ in addition to supramolecular architectures based upon helicates, ${ }^{23,24,25}$ expanded macrocycles, ${ }^{26}$ coordination cages, ${ }^{27,28}$ and other synergistic weak interactions. ${ }^{29}$ Conversely, the accessibility of covalent heteropolymetallic trivalent lanthanide complexes is challenging due to the comparable chemical properties and hence reactivity across the period, distinguishable only in their ionic radii with minute change in preferred coordination numbers and geometries. Despite this, heteropolymetallic architectures have been prepared via statistical approaches, ${ }^{14,15}$ by thermodynamic control of the coordination at specific sites ${ }^{30,31}$ or by refined approaches including post-synthetic modification strategies, ${ }^{32,33,34,35,36}$ orthogonal ligand deprotection, ${ }^{37}$ or through careful ligand design, which can resolve these minor differences. ${ }^{38,39,40}$ 
(a)

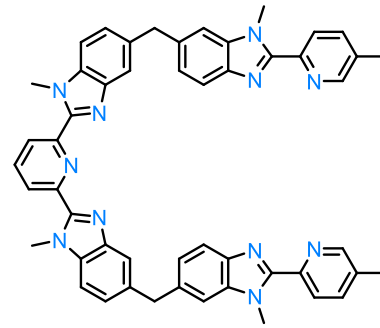

(i) $\mathrm{Cr}^{\prime \prime}, \mathrm{Er}{ }^{\prime \prime \prime}$

(ii) ox. $\rightarrow \mathrm{Cr}^{\prime \prime}$

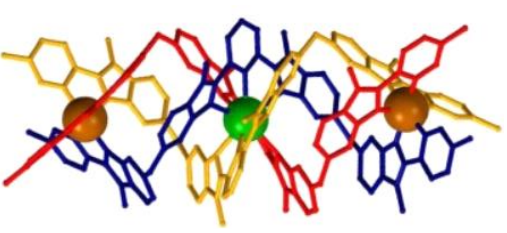

$$
C r^{\prime \prime \prime}-\mathrm{Ln}^{\text {III}}-\mathrm{Cr} \mathrm{r}^{\prime \prime \prime}
$$

(b)

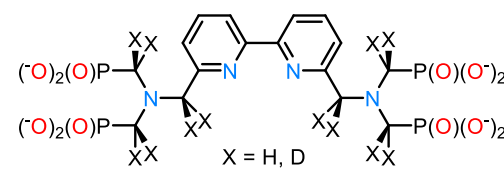

(i) $\mathrm{Yb}^{\text {III }}$

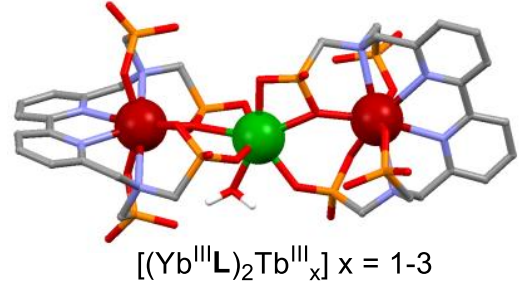

(c)

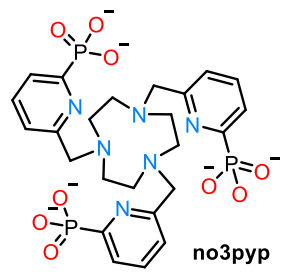

(i) $\mathrm{Yb}^{\text {III }}$

(ii) $\mathrm{Tb}^{\prime \prime \prime}$

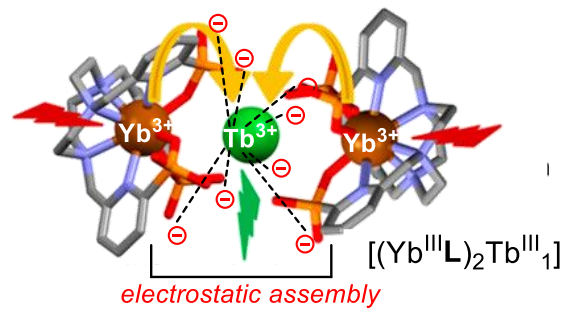

Figure 1.

Previous

examples of controlled heteropolynuclear supramolecular assemblies displaying energy transfer;

(a) Piguet's Cr-Ln-Cr helicate, ${ }^{41}$ (b) phosphonated bipyridine complexes, ${ }^{48}$ and (c) tacn trispyridyl-6-phosphonate complexes. ${ }^{55}$

In recent years heteropolymetallic complexes have shown significant utility in the burgeoning field of molecular upconversion (UC), ${ }^{42,43,44}$ consisting in the conversion of low energy photons into higher energy ones. This work was pioneered by Piguet et al. who reported the seminal example of solution state molecular upconversion in a $\mathrm{Cr}_{2} \mathrm{Eu}$ helicate (Figure 1a). ${ }^{38,45}$ While this first example is a $d-f$ hybrid it demonstrates the utility of supramolecular assemblages in the formation of discrete heteropolynuclear complexes from labile metal precursors. In our laboratories we have built on a kinetic approach to form pure $f$-assemblies, in this case exploiting the strong interactions between $\mathrm{Ln}^{3+}$ and phosphonate functions. ${ }^{46}$ Designing phosphonate 
functionalised complexes which contain supplementary negatively charged oxygen donors enabled us to direct the coordination to additional lanthanide ions. ${ }^{47,48}$ These form in aqueous solution $(\mathrm{pH}=7)$ via a combination of coordination and favourable electrostatic interactions between the negatively charged phosphonate donors and the cationic $\mathrm{Ln}^{3+}$ ions. In a first example an octadentate phosphonate functionalised bipyridine ligand chelated $\operatorname{Ln}^{3+}$ formed 1:1 stoichiometric complexes. Upon further addition of $\mathrm{Ln}^{3+}$ ions, this initiated formation of several heteropolynuclear assemblies (Figure 1b, $[\mathrm{LnL}]_{2} \mathrm{Ln}$ ', $[\mathrm{LnL}]_{2} \mathrm{Ln}_{2}$, and $[\mathrm{LnL}]_{2} \mathrm{Ln}_{3}{ }_{3}$ ) with no metal exchange at neutral $\mathrm{pH}$ between the Ln cation complexed by the ligands and the Ln' outside. Importantly, using the deuterated version of the ligand, upconversion could be observed in $\mathrm{D}_{2} \mathrm{O}$ via efficient energy transfer between two $\mathrm{Yb}^{3+}$ complex as donors and $\mathrm{Tb}^{3+}$ cations as acceptors, exhibiting characteristic $\mathrm{Tb}^{3+}$ emission in the visible region upon excitation of the $\mathrm{Yb}^{3+}$ in the near infra-red (NIR).

The strong chelation of lanthanide ions is important to enable control of their hierarchical assemblies and to limit their toxicity for potential biological applications. This is achieved by multidentate chelating ligands ensuring full encapsulation. Typically, such ligands are largely based upon azamacrocycles with oxo-functionalities, such as the prototypical dota, ${ }^{49}$ a $(1,4,7,10$ tetraazacyclododecane) tetraacetate ligand. A panoply of substituted azamacrocyclic ligands have previously been reported using picolinate, ${ }^{50,51}$ and phosphonate functionalities. ${ }^{52,53} \mathrm{We}$ recently reported a heteropolynuclear assembly utilising a tri-substituted 1,4,7-triazacyclononane macrocycle (tacn) containing a hybridization of these ligand types; a 6-phosphonated pyridine $\mathrm{Yb}^{3+}$ complex (Figure 1c) ${ }^{54}$ These 1:1 complexes display $C_{3}$ symmetry in solution and present a convergent arrangement of negatively charged phosphonated donors capable of coordination to a 
second metal, forming $\left[(\mathrm{YbL})_{2} \mathrm{~Tb}_{\mathrm{x}}\right](\mathrm{x}=1$ or 2$)$ sandwich complexes with $\mathrm{Tb}^{3+}$ ions, allowing for the first time observation of UC in an aqueous solution at the molecular scale. ${ }^{55}$

This work aims to build on previous work and design difunctionalised analogues of those previously described using a cyclam (1,4,8,11-tetraazacyclotetradecane) macrocyclic scaffold. It has been shown that subtle ligand effects and ligand geometries ${ }^{56}$ can drastically alter the relative stabilities of dynamically assembled polynuclear species in solution. ${ }^{57,58}$ In this case we anticipate that difunctionalised cyclam pyridyl phosphonate such as ligands $\mathbf{L}_{\mathbf{1}}$ and $\mathbf{L}_{\mathbf{2}}(\mathbf{C h a r t} \mathbf{1})$ will present a different arrangement of the phosphonate, hence promoting the formation of higher order supramolecular assemblies in solution. $\mathbf{L}_{\mathbf{2}}$ was originally designed specifically for this purpose, since the presence of the ethyl $N, N$-cross-bridge should reinforce the propensity of the macrocycle to adopt this desired convergent arrangement of phosphonates for lanthanide coordination, as already demonstrated by us. ${ }^{50,59}$
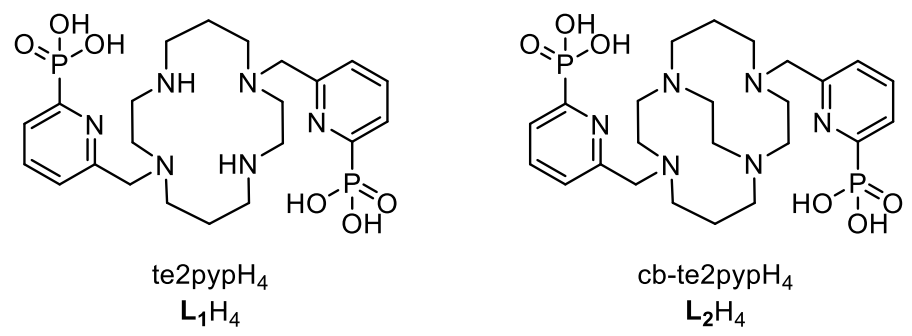

Chart 1. Structures of $\mathbf{L}_{1} \mathrm{H}_{4}\left(\mathbf{L}_{\mathbf{1}}=\right.$ te2pyp $)$ and $\mathbf{L}_{2} \mathrm{H}_{4}\left(\mathbf{L}_{\mathbf{2}}=\right.$ cb-te2pyp $)$ ligands.

\section{Results and Discussion}

\section{Ligand Synthesis and Structural Properties}

The synthetic protocol for the preparation of the ligands is depicted in Scheme 1 and full experimental details can be found in the experimental section. 

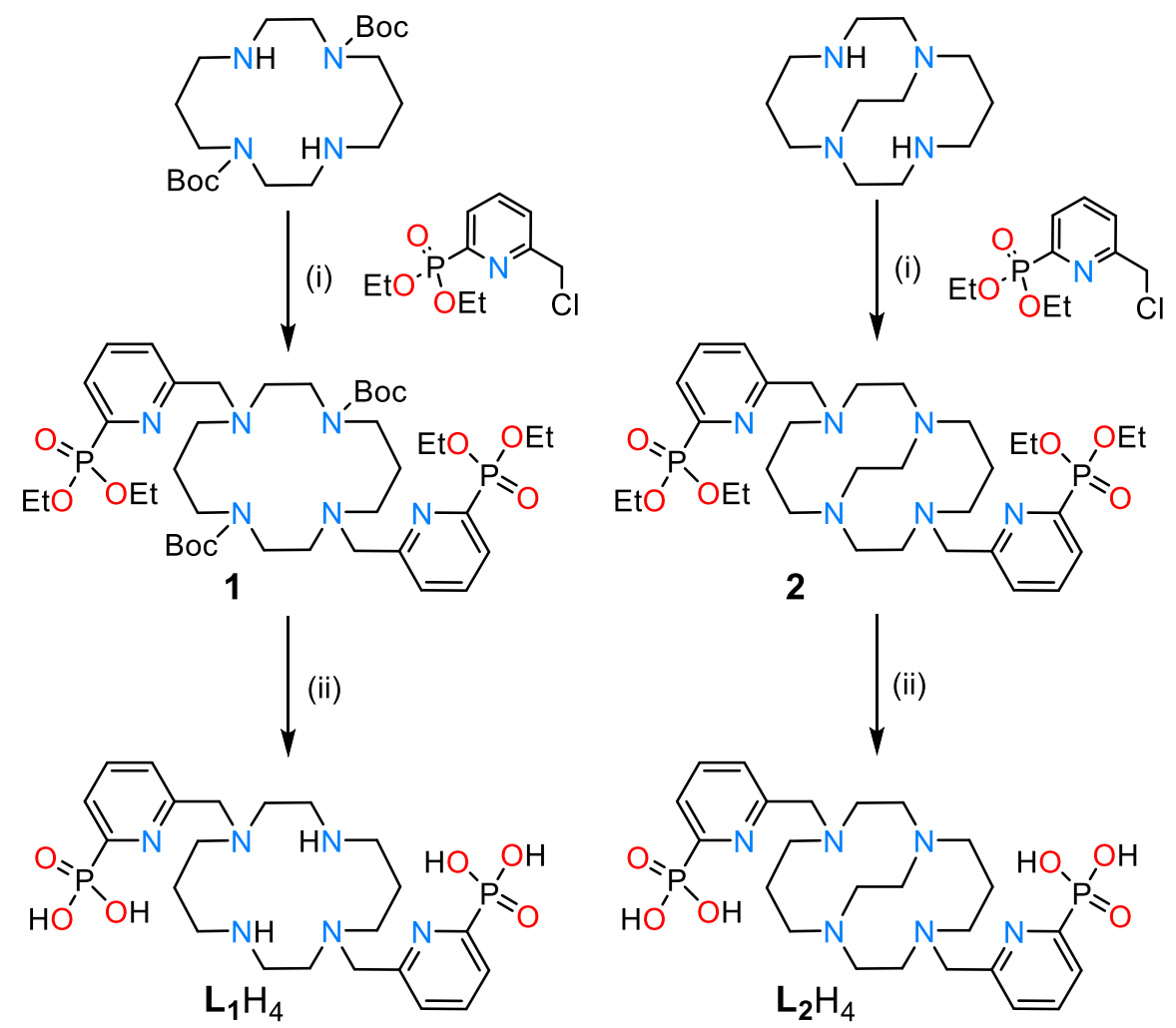

Scheme 1. Synthetic protocol for the preparation of the ligands; $\mathbf{L}_{1} \mathrm{H}_{4}$ and $\mathbf{L}_{2} \mathrm{H}_{4}$; (i) $\mathrm{K}_{2} \mathrm{CO}_{3}, \mathrm{MeCN}$, RT, 36 h (1 52\%; 2 78\%) (ii) $6 \mathrm{M} \mathrm{HCl}_{(\mathrm{aq})}, 100^{\circ} \mathrm{C}, 36 \mathrm{hr}\left(\mathbf{L}_{1} \mathrm{H}_{4} 75 \% ; \mathbf{L}_{2} \mathrm{H}_{4} 59 \%\right)$

The cyclam ligands were crystallised in their neutral forms (i.e. zwitterionic species $\mathrm{L}_{1} \mathrm{H}_{4}$ or $\mathbf{L}_{2} \mathrm{H}_{4}$, vide infra) by slow evaporation of aqueous solutions of the ligands. Single crystal X-ray diffraction analysis for $\mathbf{L}_{1} \mathrm{H}_{4}$ reveals that the molecule crystallises in a centrosymmetric conformation with a divergent arrangement of the two pyridyl phosphonic moieties, which flank the central diprotonated cyclam macrocycle. The structure displays intramolecular hydrogenbonding between the secondary nitrogen atoms of the macrocycle and the nitrogen atom of the pyridine arm $(\mathrm{N} 1-\mathrm{N} 3=3.02941(2) \AA)$, and co-crystallises with two molecules of $\mathrm{H}_{2} \mathrm{O}$ in the asymmetric unit (Figure 2). The crystal packing consists of columnar arrangements of $\mathbf{L}_{1}$ with offset intramolecular aromatic stacking, which mainly consists of hydrogen bonding between protonated macrocyclic nitrogen atoms and adjacent phosphonate groups (N3-O1 = 2.7374(2) $\AA$ ) 
and intramolecular phosphonate $\mathrm{H}$-bonds $(\mathrm{O} 3-\mathrm{O} 3=2.5817(2) \AA)$. In addition, intermolecular $\mathrm{CH}-$ $\pi$ interactions are observed between the pyridine arms and neighbouring aromatic methylene moieties $\left(\mathrm{Cnt}_{\mathrm{N1} 1-\mathrm{Cl}-\mathrm{C2}-\mathrm{C} 3-\mathrm{C} 4-\mathrm{C} 5-\mathrm{C} 6}=3.5053(3) \AA\right)$ (See Supplementary Information for crystal packing, Section 3.1).

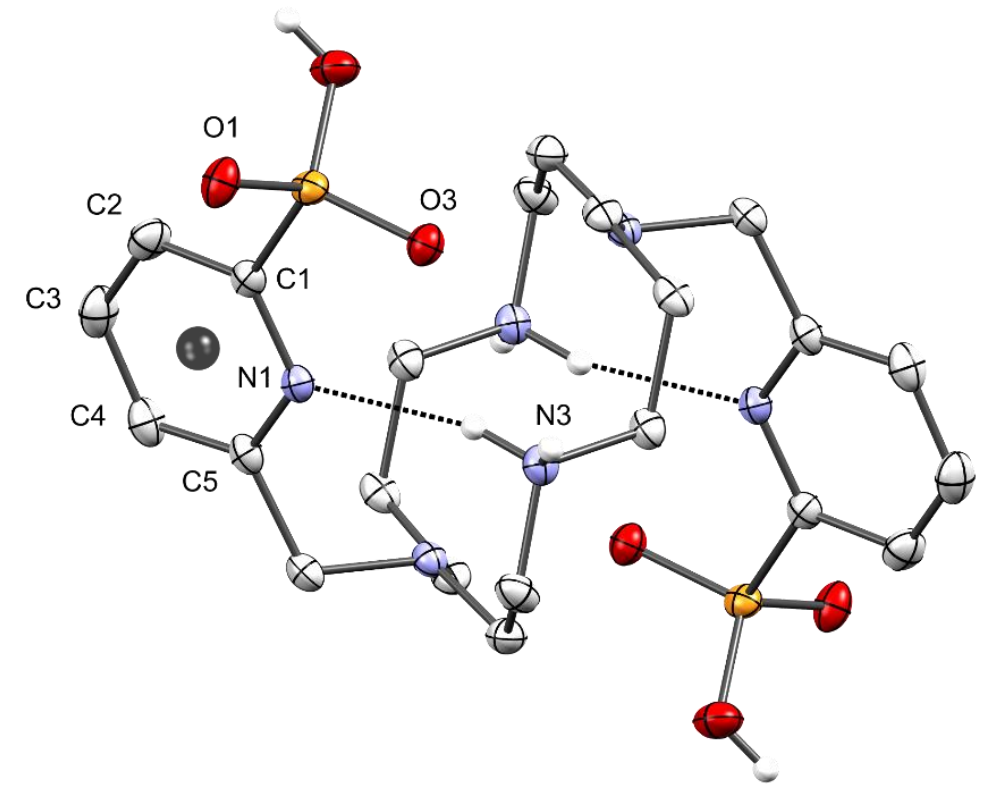

Figure 2. Single crystal X-ray structure of $\mathrm{L}_{1} \mathrm{H}_{4}$ (ellipsoids are plotted at the $50 \%$ probability level; non-heteroatom H-atoms omitted for clarity; centroid depicted as a black sphere; the dotted line represents intramolecular $\mathrm{H}$ bonding interactions)

Conversely the solid-state structure of $\mathbf{L}_{2} \mathbf{H}_{4}$ shows that the molecule crystallises in a noncentrosymmetric conformation, with a syn arrangement of the pyridyl phosphonate arms with pseudo $C_{2}$ symmetry (Figure 3). This syn structure is enforced by the requirement of the crossbridged azamacrocycle, which results in a closed configuration and contiguity of the two pyridyl functionalities. In the solid-state, this closed state is augmented by intramolecular $\pi$ - $\pi$ stacking between the two pyridyl groups $\left(\mathrm{Cnt}_{\mathrm{Ar}}-\mathrm{Cnt}_{\mathrm{Ar}}=3.6287(1) \AA\right)$, and intramolecular hydrogen bonding between the nitrogen atoms of the bis-protonated cross-bridged cyclam cavity (N2-N3 $=2.7228$ (1) 
$\AA$; N4-N5 = 2.7550(1) $\AA$ ) (See Supplementary Information, Section 3.2). It is important to note that in both cases the neutral zwitterionic forms have been crystallised in agreement with the potentiometric data determined for $\mathbf{L}_{1} \mathrm{H}_{4}$ and $\mathbf{L}_{2} \mathrm{H}_{4}$ (vide infra). Both $\mathbf{L}_{1}$ and $\mathbf{L}_{2}$ indeed behave as amphoteric compounds with basic macrocyclic amines and acidic phosphonates. These markedly different hydrogen bonds networks seen for $\mathbf{L}_{1} \mathrm{H}_{4}$ and $\mathbf{L}_{2} \mathrm{H}_{4}$ in the solid state agree well with these acido-basic properties.

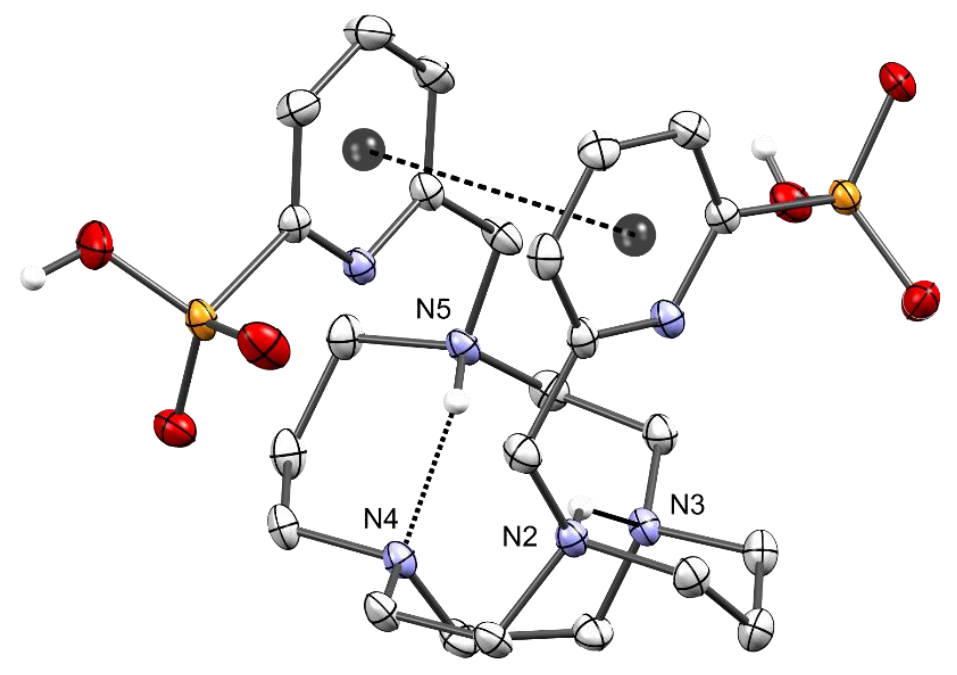

Figure 3. Single crystal X-ray structure of $\mathrm{L}_{2} \mathrm{H}_{4}$ (ellipsoids are plotted at the $50 \%$ probability level; non-heteroatom $\mathrm{H}$-atoms omitted for clarity; centroids depicted as black spheres)

\section{Complex Synthesis and Structural Properties}

Having prepared the target cyclam ligands, complexation titrations were undertaken and followed by ${ }^{1} \mathrm{H}$ NMR $\left(\mathrm{D}_{2} \mathrm{O}, \mathrm{pD}=6.5-7.0\right.$, unbuffered; $\mathrm{pH}$ equilibrated after each addition, 400 $\mathrm{MHz}, 298 \mathrm{~K}, c a .40 \mathrm{mM}$ ). Initial investigations revealed that full complexation of $\mathbf{L}_{1} \mathrm{H}_{4}$ with $\mathrm{LuCl}_{3} .6 \mathrm{H}_{2} \mathrm{O}$ did not occur at ambient temperature, instead an intermediate species with a single set of broad resonances was observed ( $c a .0 .5$ eq. $\mathrm{LuCl}_{3}$ ). As $\mathbf{L}_{1}$ and $\mathbf{L}_{2}$ display negatively charged 
phosphonate units at $\mathrm{pD}$ 6.5-7.0 and coexist as a mixture of $\mathbf{L}_{\mathbf{1}} \mathrm{H}_{3}{ }^{-} / \mathbf{L}_{1} \mathrm{H}_{2}{ }^{2-}$ and $\mathbf{L}_{2} \mathrm{H}_{4} / \mathbf{L}_{2} \mathrm{H}_{3}{ }^{-} / \mathbf{L}_{2} \mathrm{H}_{2}{ }^{2-}$ respectively (See potentiometric studies, vide infra), the observation that the $\mathrm{pD}$ of the solution is relatively insensitive to this initial complexation lead us to postulate that the intermediate complex involves chelation of the negatively charged pendant phosphonate groups only. Full complexation and sequestration of the metal within the macrocyclic cavity would liberate $\mathrm{HCl}$ from the protonated amines and thus drastically lower the $\mathrm{pD}$ of the solution. Thus, formation of the desired complexes was achieved by heating $\left(\mathrm{D}_{2} \mathrm{O}, \mathrm{pD}=6.5-7.0,80^{\circ} \mathrm{C} 18 \mathrm{~h}\right)$ and was monitored by ${ }^{1} \mathrm{H}$ NMR to enable accurate addition of the $\mathrm{LnCl}_{3} \cdot 6 \mathrm{H}_{2} \mathrm{O}\left(\mathrm{Ln}^{3+}=\mathrm{Lu}, \mathrm{Eu}, \mathrm{Tb}, \mathrm{Yb}\right)$, ensuring formation of a stoichiometric 1:1 metal-ligand complex (Figure 4 for $\mathrm{LuCl}_{3}$ ).

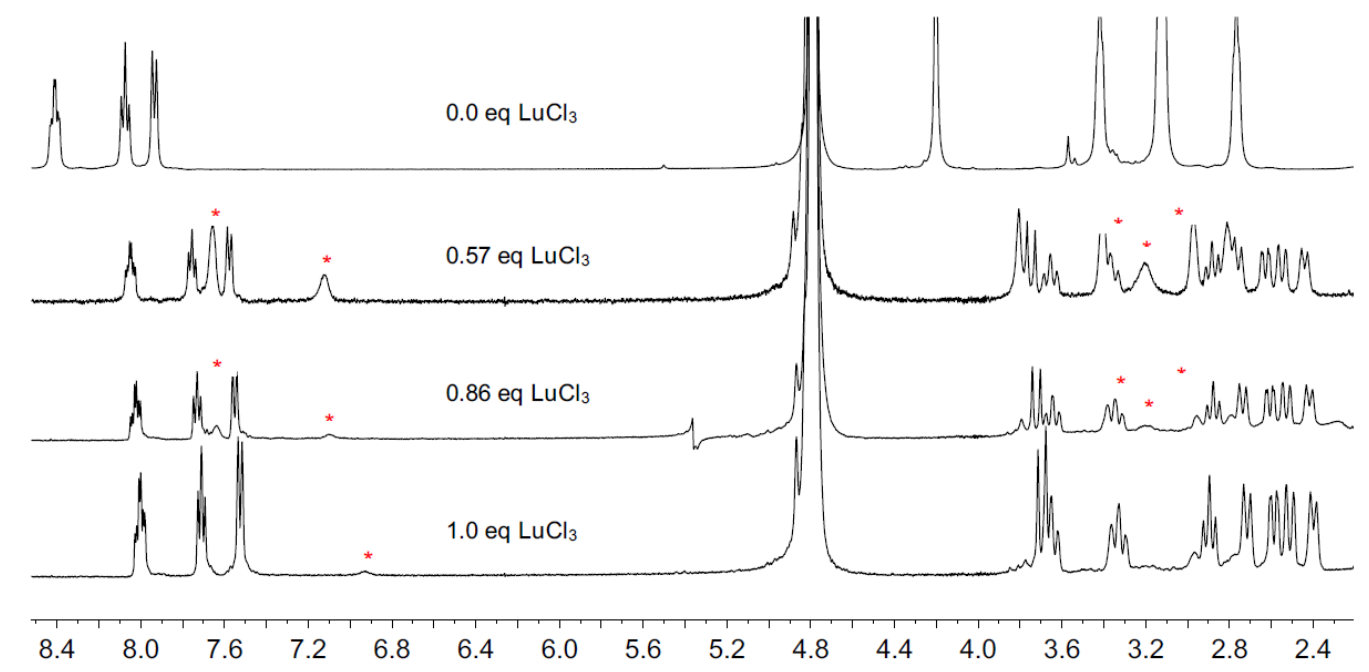

Figure 4. ${ }^{1} \mathrm{H}$ NMR $\left(\mathrm{D}_{2} \mathrm{O}, \mathrm{pD}=6.5-7.0,298 \mathrm{~K}, 400 \mathrm{MHz}\right)$ titration experiment of $\mathbf{L}_{1} \mathrm{H}_{2}$ in the presence of increasing amounts of $\mathrm{LuCl}_{3}$ after heating at $80^{\circ} \mathrm{C}$ (putative intermediate phosphonate Lu complex marked with an asterisk)

These complexes were acidified $\left(\mathrm{pD}=3.5-4.0, \mathrm{Ln}^{3+}=\mathrm{Lu}, \mathrm{Tb}, \mathrm{Yb} ; \mathrm{pD}=5.3, \mathrm{Ln}^{3+}=\mathrm{Eu}\right)$ and isolated after purification by reverse phase chromatography (Scheme 2). In the case of europium, instability at low $\mathrm{pH}$ under elevated temperatures $\left(50^{\circ} \mathrm{C}\right)$ was observed. We also attempted synthesis of the corresponding lanthanum derivative which formed intractable mixtures under 
identical complexation conditions and ultimately decomposed upon acidification $(\mathrm{pD}=3.5-4.0)$. This instability is attributed to the larger ionic radii of lanthanum - and to a lesser extent europium - suggesting that $\mathrm{Ln}^{3+}$ is not fully encapsulated in the macrocyclic cavity in the case of the larger $\mathrm{Ln}^{3+}$ cations (vide infra). For the cross-bridged congener $\mathbf{L}_{2} \mathrm{H}_{4}$ it was not possible to obtain the target complexes under identical conditions, even when utilising extended reaction times or elevated temperatures under microwave irradiation. The sterically hindered X-ray structure of $\mathbf{L}_{\mathbf{2}}$ suggests that accessibility of the central cavity is limited, a consequence of the rigid cross-bridged and encumbrance of the bulky pyridyl phosphonate arms, and is the likely explanation behind the inability to form the desired complexes; indeed, except very few examples, cross-bridged cyclam variants typically display slower complexation kinetics than their simple cyclam analogues. ${ }^{60,61}$
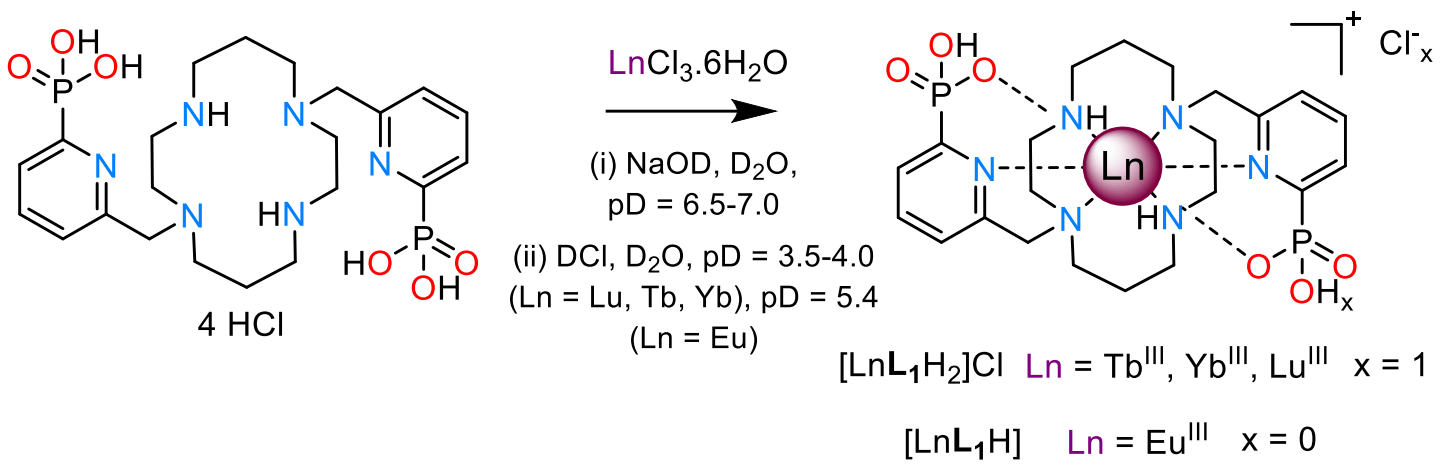

Scheme 2. Synthesis of the lanthanide complexes $\left[\mathrm{LnL}_{1} \mathrm{D}_{2}\right] \mathrm{Cl}\left(\mathrm{Ln}^{3+}=\mathrm{Eu}, \mathrm{Tb}, \mathrm{Yb}, \mathrm{Lu}\right)$ and $\left[\operatorname{Ln} \mathbf{L}_{1} \mathrm{D}\right]\left(\operatorname{Ln}^{3+}=\mathrm{Eu}\right)$

Single crystals were obtained for EuL $\mathrm{L}_{1} \mathrm{D}$ by evaporation of a $\mathrm{H}_{2} \mathrm{O}(\mathrm{pH} \approx 7)$ solution and the elucidated structure displays the neutral complex containing one monoprotonated and one fully deprotonated phosphonate function (Figure 4), in agreement with the physico-chemical data (vide infra). The compound crystallises in the non-centrosymmetric $P 21 / c$ space group, with four molecules in the unit cell. The molecule is pseudo $C_{2}$ symmetric and eight-coordinate in the solidstate with six nitrogen donors (four azamacrocyclic and two pyridine nitrogen atoms), and two 
oxygen donors from the pendant phosphonate groups, and exhibits significantly distorted square anti-prismatic geometry. The compound displays helical chirality and exists in the solid-state as a racemic mixture, two $\Delta$ and two $\Lambda$ isomers. Examination of the top-down space-fill view of the structure reveals that the bound ion is well protected, indicating that ligation in the ninth coordination site is sterically encumbered, discouraging ligation of another ligand such as $\mathrm{H}_{2} \mathrm{O}$. The europium ion exhibits typical Ln-N distances for cyclam complexes (Eu1-N: N2 $=2.6196(3)$ $\AA, \mathrm{N} 3=2.5835(3) \AA, \mathrm{N} 4=2.6320(2) \AA, \mathrm{N} 5=2.5896(3) \AA),{ }^{50}$ with shortened pyridine nitrogen distances (Eu1-N: N1 = 2.5448(3) $\AA, \mathrm{N} 6=2.5186(4) \AA)$, and Eu1-O distances of 2.2313(3) $\AA$ $(\mathrm{O} 1)$ and 2.2725(3) $\AA(\mathrm{O} 4)$. The europium ion is bound in an exocyclic fashion above the cyclam

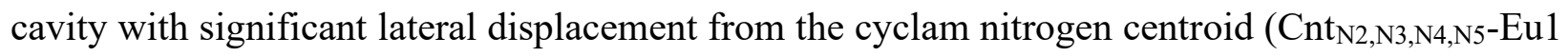
$=1.5400(2) \AA)$. The molecular packing in the structure is perpetuated through hydrogen bonding of the phosphate groups, notably a head-to-tail configuration via the azamacrocyclic $\mathrm{NH}$ atoms which are divergent from the europium center and interact with a neighbouring phosphonate group (O5-N3 = $3.1659 \AA$; O5-N5 = $3.0164 \AA$ ), in addition to H-bonding with the included $\mathrm{H}_{2} \mathrm{O}$ solvent molecules in the structure $(\mathrm{O} 3-\mathrm{O} 7=2.5209(4) \AA, \mathrm{O} 2-\mathrm{O} 9=2.8338(4) \AA, \mathrm{O} 2-\mathrm{O} 10=2.9205(3) \AA)$. The propensity of the phosphonate groups as H-bond acceptors highlights their capacity as ditopic ligands, capable of interacting with multiple electropositive moieties simultaneously, and is promising with respect to formation of polynuclear architectures. 


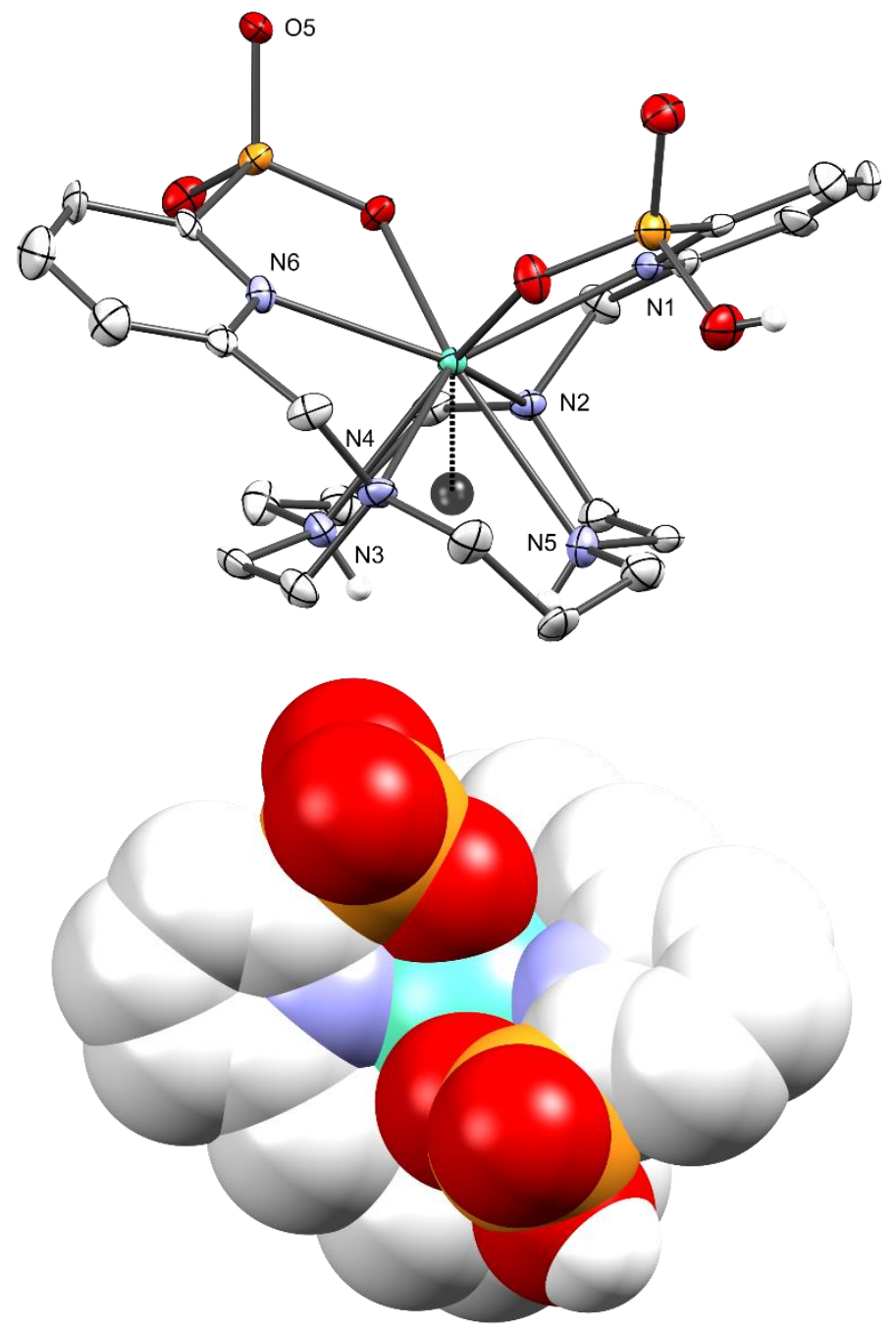

Figure 4. (left) Single crystal X-ray structure of $\left[\mathrm{EuL}_{1} \mathrm{D}\right]$ (ellipsoids are plotted at the $50 \%$ probability level; non-heteroatom $\mathrm{H}$-atoms and solvent are omitted for clarity; centroid depicted as a black sphere); (right) Space-fill representation

\section{Potentiometric Acido-Basic Properties}

The ligand $\mathbf{L}_{1}$ and its bridged analogue $\mathbf{L}_{2}$ both contain four amino functions, two pyridine and two phosphonate moieties. Thus, ten ionizable units lead to the formation of various protonated species. Potentiometric measurements were undertaken $(\mathrm{pH} \approx 2.5-11)$ to characterise the majority of them (See Supplementary Information, Section 4). Some of the protonation constants were 
indeed difficult to measure with high accuracy due to their low values $\left(\log K^{\mathrm{H}}<<2\right.$, vide infra $)$. Table 1 summarises the data resulting from the statistical processing of the potentiometric data.

For $\mathbf{L}_{\mathbf{1}}$, five protonation constants were accurately determined, while only four $\mathrm{p} K_{\mathrm{a}}$ values were calculated for its bridged analogue $\mathbf{L}_{2}$. For $\mathbf{L}_{1}$, the two highest protonation constants $\left(\log K_{1 \mathrm{H}}=\right.$ $11.17(3)$ and $\left.\log K_{2 \mathrm{H}}=10.87(3)\right)$ were easily attributed to the two secondary amines, in agreement with solid-state structural data (Figure 2) and were found to be comparable to those measured for related systems such as cyclam $\left(\log K_{11}=11.29\right.$ and $\log K_{12}=10.19(1),{ }^{62} \log K_{11}=11.585(5)$ and $\left.\log K_{12}=10.624(4)^{63}\right)$, and cyclam bis-picolinate (te2pa, $\log K_{11}=11.12(2)$ and $\log K_{12}$ $=10.36(1)) \cdot{ }^{64}$ The two other protonation constants of the macrocyclic cyclam scaffold (i.e. the two tertiary amines) were estimated to be lower than 2.5 (e.g. $\log K_{13}=2.43^{65} / 2.27^{66}$ and $\log K_{14}=$ $1.97^{64} / 1.43^{68}$ for cyclam), primarily due to Coulombic repulsions between the positive charges resulting from the successive protonation of the secondary and tertiary amines of the cyclam subunit. In agreement with cb-te2pa, the first protonation constant of $\mathbf{L}_{2}$ was too high to be accurately determined $\left(\log K_{1 \mathrm{H}}>13\right)$. Only the second protonation for the amino function of the azamacrocyclic backbone was evaluated $\left(\log K_{2 \mathrm{H}}=9.55(3)\right)$ in agreement with the values determined previously for cb-cyclam $\left(\log K_{2 \mathrm{H}}=10.20\right)^{67}$ and cb-te2pa $\left(\log K_{2 \mathrm{H}}=9.55(4)\right)^{56}$ (Table 1). Indeed, cb-cyclam, cb-te2pa and $\mathbf{L}_{2}$ characterised by a first protonation constant (log $K_{11}=12.42,13.01$ and $>13$ respectively) much higher than that of the corresponding parent cyclam, te2pa and $\mathbf{L}_{1}\left(\log K_{11}=11.29,11.12\right.$ and 11.73 respectively). To rationalise these properties, stabilization of the first proton by intramolecular hydrogen bonds and solvation effects has been proposed. ${ }^{66}$ Likewise, the second protonation step is more difficult and agrees with the drastic decrease of the corresponding $\mathrm{p} K_{\mathrm{a}}$ values $\left(\log K_{12}=10.20\right.$ for $\mathbf{c b}$-cyclam, $\log K_{12}=9.55$ for cb-te2pa, $\log K_{12}=9.55$ for $\mathbf{L}_{2}$ ). 
The following two protonation constants of $\mathbf{L}_{1}\left(\log K_{13}=6.71(6)\right.$ and $\left.\log K_{14}=5.82(6)\right)$ and $\mathbf{L}_{2}$ $\left(\log K_{13}=7.38(5)\right.$ and $\left.\log K_{14}=6.51(6)\right)$ have been assigned to the first protonation constants of each of the two opposite phosphonate $-\mathrm{PO}_{3}{ }^{2-}$ units (i.e. $\mathrm{RPO}_{3}{ }^{2-}+\mathrm{H}^{+} \leftrightarrow \mathrm{RPO}_{3} \mathrm{H}^{-}$), while the second protonation constants of the protonated phosphonate groups (i.e. $\mathrm{RPO}_{3} \mathrm{H}^{-}+\mathrm{H}^{+} \leftrightarrow \mathrm{RPO}_{3} \mathrm{H}_{2}$ ) were estimated to be negligible, lower than 2. As a consequence, $\mathbf{L}_{\mathbf{1}}$ and $\mathbf{L}_{\mathbf{2}}$ predominate as $\mathbf{L}_{\mathbf{x}} \mathrm{H}_{2}{ }^{2-}$ and $\mathbf{L}_{\mathbf{x}} \mathrm{H}_{3}{ }^{-}$species $(\mathbf{x}=1$ or 2$)$ at $\mathrm{pH} 7.0$ (See Supplementary Information, Section 4).

In the case of $\mathbf{L}_{\mathbf{1}}$, we determined a fifth protonation constant $\left(\log K_{15}=2.70(6)\right)$ that was attributed to one (or both) of the pyridine function(s) (vide infra). This is in agreement with reported data on amino-phosphonated-pyridine derivatives. ${ }^{6}$ For L2, we were unable to evaluate accurately this corresponding protonation constant and the $\log K_{15}$ value was estimated to be $<<$ 2. For $\mathbf{L}_{1}$ and $\mathbf{L}_{2}$, the other protonation constants (i.e. the two amine functions of the cyclam scaffold, two phosphonate protonation sites and the pyridine units) were estimated to be low $(<2)$ and could not be determined.

To confirm the $\mathrm{p} K_{\mathrm{a}}$ values of $\mathbf{L}_{1}$ and $\mathbf{L}_{2}$ deduced by potentiometric means, spectrophotometric titrations were conducted $\left(\lambda_{\mathrm{abs}}=220-500 \mathrm{~nm}\right)$ as a function of $\mathrm{pH}$ (See Supplementary Information, Section 4)). In all cases, the aromatic pyridine groups constitute the main chromophores $\left(\pi-\pi^{*}\right.$ transitions centered around ca. $\left.270 \mathrm{~nm} ; \varepsilon \approx 10^{4} \mathrm{M}^{-1} \mathrm{~cm}^{-1}\right)$. For $\mathbf{L} \mathbf{1}$, marked spectral variations were mainly observed in acidic and basic $\mathrm{pH}$ ranges. The statistical processing of the absorption spectrophotometric data against $\mathrm{pH}$ allowed accurate determination of three protonation constants. The most acidic protonation $\left(\log K_{15}=2.5(2)\right)$ induces the largest spectral amplitude change (i.e. hyperchromic shift) and is attributed to one (or two) pyridine functions. This value is in excellent agreement with the value obtained by potentiometry $\left(\log K_{15}=2.70(6)\right)$. An analogous protonation constant could not be determined accurately for the $\mathbf{L}_{2}$ analogue, thus 
indicating that this $\mathrm{p} K_{\mathrm{a}}$ value is $<<2$, in agreement with the overall basicity decrease of the crossbridged cyclam scaffold.

At the other end of the $\mathrm{pH}$ scale, the most basic site (i.e. mean value between $\log K_{11}$ and $\log$ $K_{12}$ for $\mathbf{L}_{1}$ and $\log K_{12}$ for $\mathbf{L}_{2}$ ) was assigned to the cyclam amine functions that can interact in a non-covalent manner (i.e. hydrogen bonding with a 5-membered ring being formed upon protonation of the amine and subsequent hydrogen bonding with $\mathrm{N}_{\mathrm{pyr}}$ ) with the chromophoric pyridine subunit (Figure 2). For $\mathbf{L}_{1}$, spectral changes at basic $\mathrm{pH}$ were relatively weak compared to marked changes for $\mathbf{L}_{2}$, indicating that the pyridine chromophores interact more strongly in the case of $\mathbf{L}_{2}$ with the cb-cyclam scaffold. This can be related to $\pi$ - $\pi$ stacking interactions between the two pyridine units upon protonation of the cross-bridged cyclam scaffold.

The other protonation constants (i.e. mean value between $\log K_{13}$ and $\log K_{14}$, Table 1) measured both for $\mathbf{L}_{1}$ and $\mathbf{L}_{2}$ were attributed to the phosphonate groups. The deprotonation of these functions has very little influence on the pyridine chromophores of these macrocyclic ligands as shown by the weak spectral variations measured at neutral to weakly acidic $\mathrm{pH}$.

Consequently, the introduction of an ethylene cross-bridge in $\mathbf{L}_{2}$ significantly alters the acidbase properties of the macrocyclic chelator, in particular those of the amine functions (i.e. stabilization of the first proton, $c f$. cyclam $v s$. cb-cyclam). This is in line with the markedly different hydrogen bonds network seen in the solid state for $\mathbf{L}_{1} \mathrm{H}_{4}$ and $\mathbf{L}_{2} \mathrm{H}_{4}$ (Figures $\mathbf{2}$ and $\mathbf{3}$ ). 
Table 1. Protonation constants $\left(\log \mathrm{K}_{\mathrm{nH}}\right)^{a}$ for ligands $\mathbf{L}_{\mathbf{1}}$ and $\mathbf{L}_{\mathbf{2}}$ compared to literature data reported for closely related systems.
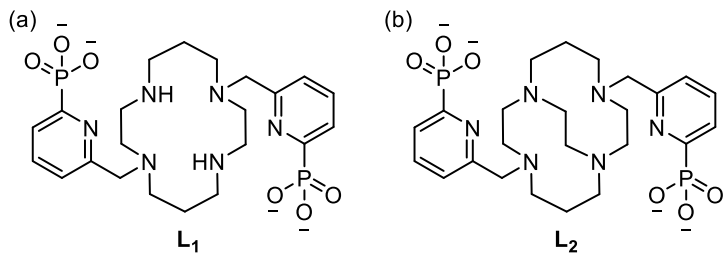

(c)
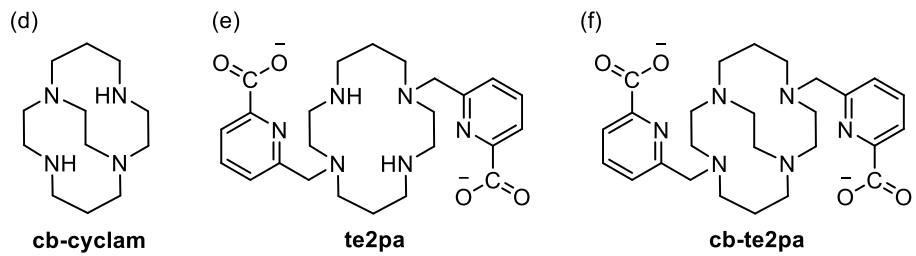

cb-cyclam

$\log K_{\mathrm{H}}( \pm 3 \sigma)$

\begin{tabular}{|c|c|c|c|c|c|c|}
\hline Protonation site & $\mathrm{L}_{1}$ & $\mathrm{~L}_{2}$ & cyclam ${ }^{61}$ & $\begin{array}{l}\text { cb- } \\
\text { cyclam }^{67}\end{array}$ & te $2 \mathrm{pa}^{64}$ & $\begin{array}{l}\text { cb- } \\
\text { te2pa }\end{array}$ \\
\hline \multicolumn{7}{|l|}{ Equilibrium } \\
\hline $\mathrm{L}+\mathrm{H} \leftrightarrows \mathrm{LH} ; \log K_{11}$ & $11.17(3)^{b, e}$ & $>13^{\mathrm{e}}$ & $11.29^{\mathrm{e}}$ & $12.42^{\mathrm{e}}$ & $11.12(2)^{\mathrm{e}}$ & $13.01(2)^{\mathrm{e}}$ \\
\hline \multirow{2}{*}{$\begin{array}{l}\mathrm{LH}+\mathrm{H} \leftrightarrows \mathrm{LH}_{2} ; \log \\
K_{12}\end{array}$} & \multirow[t]{2}{*}{$10.87(3)^{\mathrm{b}, \mathrm{e}}$} & $9.55(3)^{\mathrm{b}, \mathrm{e}}$ & \multirow[t]{2}{*}{$10.19^{\mathrm{e}}$} & \multirow[t]{2}{*}{$10.20^{\mathrm{e}}$} & \multirow[t]{2}{*}{$10.36(1)^{\mathrm{e}}$} & \multirow[t]{2}{*}{$9.55(4)^{\mathrm{e}}$} \\
\hline & & $9.52(2)^{\mathrm{c}, \mathrm{e}}$ & & & & \\
\hline Mean $\left(K_{11}\right.$ and $\left.\log K_{12}\right)$ & $11.1(2)^{\mathrm{c}, \mathrm{e}}$ & - & & & & \\
\hline $\begin{array}{l}\mathrm{LH}_{2}+\mathrm{H} \leftrightarrows \mathrm{LH}_{3} ; \log \\
K_{13}\end{array}$ & $6.71(6)^{b, d}$ & $7.38(5)^{\mathrm{b}, \mathrm{d}}$ & $1.61^{\mathrm{e}}$ & & $3.38(2)^{\mathrm{e}}$ & $3.27(4)^{\mathrm{e}}$ \\
\hline $\begin{array}{l}\mathrm{LH}_{3}+\mathrm{H} \leftrightarrows \mathrm{LH}_{4} ; \log \\
K_{14}\end{array}$ & $5.82(6)^{\mathrm{b}, \mathrm{d}}$ & $6.51(6)^{\mathrm{b}, \mathrm{d}}$ & $1.91^{\mathrm{e}}$ & & $2.63(1)^{\mathrm{e}}$ & $2.24(4)^{\mathrm{e}}$ \\
\hline $\begin{array}{l}\text { Mean }\left(\log K_{13} \text { and } \log \right. \\
\left.K_{14}\right)\end{array}$ & $6.1(2)^{\mathrm{c}, \mathrm{d}}$ & $6.84(6)^{\mathrm{c}, \mathrm{d}}$ & & & & \\
\hline \multirow{2}{*}{$\begin{array}{l}\mathrm{LH}_{4}+\mathrm{H} \leftrightarrows \mathrm{LH}_{5} ; \log \\
K_{15}\end{array}$} & $2.70(6)^{\mathrm{b}}$ & \multirow[t]{2}{*}{-} & & & & \\
\hline & $2.5(2)^{\mathrm{c}}$ & & & & & \\
\hline $\begin{array}{l}\mathrm{LH}_{2}+2 \mathrm{H} \leftrightarrows \mathrm{LH}_{4} ; \log \\
K_{14}\end{array}$ & & & & $1.39^{\mathrm{e}}$ & & \\
\hline
\end{tabular}


${ }^{a} I=0.1 \mathrm{M}(\mathrm{NaCl}) ; T=25.0(2){ }^{\circ} \mathrm{C} ;[\mathbf{L}] \sim 10^{-3} \mathrm{M} .{ }^{b}$ potentiometry. ${ }^{c}$ Absorption $v s . \mathrm{pH}$ titrations. ${ }^{d}$ phosphonate units. ${ }^{e}$ cyclam amino units. Charges omitted for the sake of clarity. $K_{\mathrm{lh}}=$ $\left[\mathrm{L}_{1} \mathrm{H}_{\mathrm{h}}\right] /\left[\mathrm{L}_{1} \mathrm{H}_{\mathrm{h}-1}\right][\mathrm{H}]$. Values in parentheses are standard deviations $(3 \sigma)$ in the last significant digit.

All attempts to assess the affinity of the $\mathbf{L}_{1}$ or $\mathbf{L}_{2}$ ligands for the lanthanide cations were unsuccessful. Mirroring ${ }^{1} \mathrm{H}$ NMR investigations, either complexation kinetics were extremely slow (i.e. $\mathbf{L}_{2}$ ) or stabilities with $\mathrm{Ln}^{3+}$ appears to be high (i.e. $\mathbf{L}_{1}$ ) and preclude the use of potentiometric means for their direct determination. Furthermore, in the presence of amines lanthanide ions do not lead to charge transfer electronic transitions as $\mathrm{Cu}^{\mathrm{II}}$ does, ${ }^{67,69}$ thus making it complicated to monitor by absorption spectrophotometry. Therefore, only the protonation constants of a preformed complex were determined, as these values influence the conditions required to produce polymetallic assemblies, for which phosphonate units need to be fully deprotonated. The $\mathrm{Yb}^{3+}$ complex with $\mathbf{L}_{\mathbf{1}}$ was consequently prepared by mixing a solution of $\mathbf{L}_{\mathbf{1}}(1.42 \mathrm{mM})$ to an equimolar amount of $\mathrm{Yb}^{3+}$. A slight excess of $\mathrm{NaOH}$ ( $c a .6$ equivalents) was added to the solution to ensure full deprotonation of the $\mathbf{L}_{\mathbf{1}}$ ligand and favour metal complexation. The solution was heated at 60 ${ }^{\circ} \mathrm{C}$ over two days to ensure full complexation. An aliquot of $5.5 \mathrm{~mL}$ of the solution was then used for potentiometric investigations. Statistical processing proved insightful. Even though it is an approximation, the stability of the $\mathrm{YbL}_{1}$ complex was estimated to be higher than $\log K=25$ (i.e., assuming that below $\sim 10 \%$, a species cannot be accurately quantified by potentiometric means, the speciation diagrams of the system showed that the L1 protonated are $<10 \%$ at $\mathrm{pH} 2.5$ for $\log$ $K=25$ which thus defines the upper limit of the stability of the YbL1 complex since no protonated L1 species could be detected), in agreement with the high denticity and structural arrangement of the macrocyclic chelator. Two $\mathrm{p} K_{\mathrm{a}}$ values $\left(\log K_{111}=5.74(9)\right.$ and $\log K_{112}=3.5(1)$ with $K_{\mathrm{klh}}=$ $\left.\left[\mathrm{M}_{\mathrm{k}} \mathrm{L}_{1} \mathrm{H}_{\mathrm{h}}\right] /\left[\mathrm{M}_{\mathrm{k}} \mathrm{L}_{1} \mathrm{H}_{\mathrm{h}-1}\right][\mathrm{H}]\right)$ were accordingly evaluated. On the basis of the solid-state structure of $\mathrm{Eu} \mathbf{L}_{1} \mathrm{H}$, and by comparison with phosphonate $\mathrm{p} K_{\mathrm{a}} \mathrm{S}$ in free $\mathbf{L}_{1}\left(\log K_{13}=6.71(6)\right.$ and $\log K_{14}=$ 5.82(6), vide supra), these two determined $\mathrm{p} K_{\mathrm{a}}$ values can confidently be attributed to the 
uncoordinated oxygen atoms of the phosphonate units, the $\mathrm{N}$-cyclam, $\mathrm{N}$-pyridine and two $\mathrm{O}$ phosphonate atoms being already involved in the $\mathrm{Yb}^{3+}$ binding. These $\mathrm{p} K_{\mathrm{a}}$ values are likely to be lowered with respect to the free ligand $\mathbf{L}_{1}$ as a consequence of the involvement of these units in the $\mathrm{Yb}^{3+}$ binding (i.e., EuL $\mathbf{L}_{1} \mathrm{H}$ was crystallised without any counter-anion, one of the phosphonate compensated for the positive charge of the EuLi complex).

\section{Spectroscopic Characterization of the $\left[\mathrm{LnL}_{1}\right]$ Complexes}

The UV-Visible spectrum of $\left[\mathrm{LnL}_{1}\right]^{-}\left(\mathrm{Ln}^{3+}=\mathrm{Eu}, \mathrm{Tb}, \mathrm{Yb}\right)$ recorded in tris. $\mathrm{HCl}$ buffer $(10 \mathrm{mM}$, $\mathrm{pD}=7.4$ ) is dominated by a high energy absorption band centered around $c a .270 \mathrm{~nm}$, attributed to the $\pi \rightarrow \pi^{*}$ transitions of the aromatic pyridyl phosphonate, together with a shoulder on the low energy tail, characteristic of the rigidification upon complexation of pyridyl rings. ${ }^{70}$ These absorptions are associated with extinction molar coefficient $(\varepsilon)$ of $10300 \mathrm{M}^{-1} \mathrm{~cm}^{-1}, 10500 \mathrm{M}^{-1} \mathrm{~cm}^{-}$ ${ }^{1}$ and $9400 \mathrm{M}^{-1}$ for $[\mathrm{EuL}]^{-},\left[\mathrm{TbL}_{1}\right]^{-}$, and $\left[\mathrm{YbL}_{1}\right]^{-}$respectively. The excitation spectra recorded upon metal-centered emission shows little variation compared to the corresponding absorption spectra across the metals studied, confirming the antenna effect as responsible for emission sensitization (Figure 5).

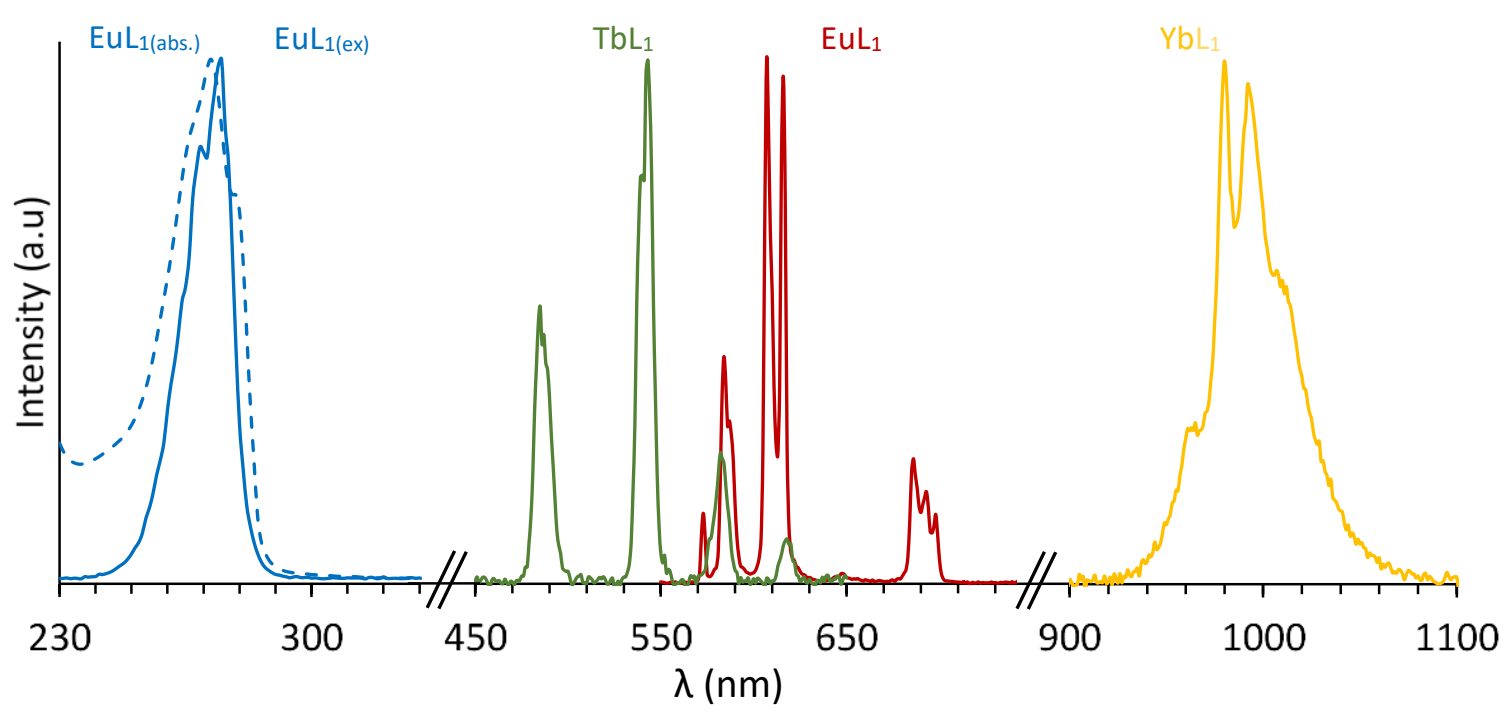


Figure 5. Absorption (---, $\left.\left[\mathrm{Eu} \mathbf{L}_{1}\right]^{-}\right)$, excitation $\left(-,\left[\mathrm{Eu} \mathbf{L}_{1}\right]^{-}, \lambda_{\mathrm{em}}=616 \mathrm{~nm}\right)$ and emission spectra $\left(\lambda_{\mathrm{ex}}\right.$ $=272 \mathrm{~nm})$ of $[\mathrm{EuL}]^{-}\left(-, 6.1 \times 10^{-5} \mathrm{M}\right),\left[\mathrm{TbL}_{1}\right]^{-}\left(-, 2.96 \times 10^{-5} \mathrm{M}\right)$, and $\left[\mathrm{YbL}_{1}\right]^{-}\left(-, 2.9 \times 10^{-5} \mathrm{M}\right)$ recorded in $\mathrm{D}_{2} \mathrm{O}$ at $293 \mathrm{~K}(\mathrm{pD}=7.4$, tris. $\mathrm{DCl}$ buffer $10 \mathrm{mM})$.

The spectroscopically silent lutetium analogue $\mathrm{LuL}_{\mathbf{1}}$ was used to determine the emissive properties of the ligand. The steady-state emission spectra of [ $\left.\mathrm{LuL}_{1}\right]$ has been measured at $77 \mathrm{~K}$ and at ambient temperature (See Supplementary Information, Section 5.1.2). From the phosphorescent emission measured at $77 \mathrm{~K}$, the energy level of the triplet state was determined to be $27930 \mathrm{~cm}^{-1}{ }^{71}$ in line with previous studies with 6-phosphonated pyridine appendages. The corresponding lifetime was found to be $462 \pm 2 \mathrm{~ms}$. As expected, the phosphorescent emission did not persist at $293 \mathrm{~K}$, reflecting the increased quenching at ambient temperature in such aerated media. The luminescent emission from the other photoactive complexes are as expected, ${ }^{72,73}$ exhibiting typical emission bands $\left(\mathrm{Eu}^{3+}={ }^{5} \mathrm{D}_{0} \rightarrow{ }^{7} \mathrm{~F}_{\mathrm{j}}\right.$ with $J=0$ to 4 ; $\mathrm{Tb}^{3+}={ }^{5} \mathrm{D}_{4} \rightarrow{ }^{7} \mathrm{~F}_{\mathrm{j}}$, with $J=5$ to 2, $\left.\mathrm{Yb}^{3+}={ }^{7} \mathrm{~F}_{5 / 2} \rightarrow{ }^{7} \mathrm{~F}_{7 / 2}\right)^{4}$ upon excitation at $272 \mathrm{~nm}$ (Table 2). The luminescence lifetimes in water and $\mathrm{D}_{2} \mathrm{O}$ allowed for the calculation of the hydration numbers, ${ }^{74,75}$ which indicate that the octacoordinated ligand generally excludes formation of solvent adducts ( $q$ values $0.1-0.3)$, as evidenced in the solid state structure of the $\mathrm{Eu}^{3+}$ complex, although some quenching is still evident, potentially due to NH oscillators. In all cases the lifetime data were perfectly fitted to monoexponential decays at $293 \mathrm{~K}$.

\begin{tabular}{llllllll}
\hline Species & $\lambda_{\text {exc }}[\mathrm{nm}]$ & $\varepsilon\left[\mathrm{M}^{-1} \cdot \mathrm{cm}^{-1}\right]^{*}$ & $\tau_{\mathrm{H}_{2} O} \mathrm{a}^{\mathrm{a}}[\mu \mathrm{s}]$ & $\tau_{D_{2} O}{ }^{\mathrm{a}}[\mu \mathrm{s}]$ & $\phi_{\mathrm{H}_{2} O}{ }^{\mathrm{b}}$ & $\phi_{D_{2} O} \mathrm{~b}$ & $q$ \\
\hline$[\mathrm{EuL}]^{-}$ & 272 & 10300 & 1260 & 1700 & 0.037 & 0.04 & 0.1 \\
{$\left[\mathrm{~Tb} \mathbf{L}_{1}\right]^{-}$} & 272 & 10500 & 2360 & 2500 & 0.17 & 0.19 & 0.2 \\
{$[\mathrm{YbL}]_{1}^{-}$} & 272 & 9400 & 2.5 & 5.6 & 0.003 & 0.006 & $0.1-0.3$
\end{tabular}

Table 2. Photophysical properties of [LnL1 $]^{-}$complexes in tris buffer $(10 \mathrm{mM} ; \mathrm{pH}=7.0$; or $\mathrm{pD}=$ $7.2\left(\left[\mathrm{~Tb}_{1}\right]^{-}\right.$and $\left.\left[\mathrm{YbL}_{1}\right]^{-}\right)$and $\left.7.4\left(\left[\mathrm{Eu} \mathbf{L}_{1}\right]^{-}\right)\right)$. 
Reference compounds for the luminescence quantum yield: $\left[\mathrm{Ru}(\text { bipy })_{3} \mathrm{Cl}_{2}\right]$ in water $(\Phi=0.04)^{76}$ as reference for $\mathrm{Eu}$, Rhodmamine $6 \mathrm{G}$ in water $(\Phi=0.81)^{77}$ as reference for $\mathrm{Tb}$ and cardiogreen (IR125) in $\mathrm{MeOH}(\Phi=0.078)$ for $\mathrm{Yb}^{.78} *$ values obtained in water. ${ }^{\mathrm{a}}$ Estimated error $\pm 10 \%$. ${ }^{\mathrm{b}}$ Estimated Error $\pm 15 \%$.

The overall luminescence quantum yield of the $\left[\mathrm{Eu} \mathbf{L}_{1}\right]^{-}$and $\left[\mathrm{Tb} \mathbf{L}_{1}\right]^{-}$complexes are rather weak, being almost half of the values obtained for complexes based on pyridyl carboxylate ${ }^{79}$ or phosphinate arms.$^{80}$ To elucidate the sensitization efficiency of the ligand, $\eta_{\text {sens }}$, and the metalcentered luminescence quantum yield of the $\mathrm{Eu}^{3+}$ complex, $\phi_{E u}^{E u}$, the radiative rate constant $k_{\text {rad }}$ was determined from the ratio of emission bands of $\mathrm{Eu}\left(\mathrm{I}(0,1) / \mathrm{I}_{\mathrm{tot}}\right)$ according to an established protocol (Table 3). ${ }^{81}$ The $\eta_{\text {sens }}$ values of 0.17 and 0.14 (respectively in $\mathrm{H}_{2} \mathrm{O}$ and $\mathrm{D}_{2} \mathrm{O}$ ) determined indicate that the efficacy of sensitization of the europium center by the ligand triplet state is a limiting factor in efficient energy transfer, ${ }^{82}$ probably as a result of the large energy gap between the triplet excited state $\left(27393 \mathrm{~cm}^{-1}\right.$, vide supra $)$ and ${ }^{5} \mathrm{D}_{0}$ level of Eu at $17,200 \mathrm{~cm}^{-1} .(\Delta \mathrm{E}>>5000$ $\left(\mathrm{m}^{-1}\right) .^{71}$

\begin{tabular}{|c|c|c|c|c|c|c|}
\hline Parameters & $\begin{array}{l}\mathrm{I}(0,1) \\
\mathrm{I}_{\text {tot }}{ }^{a}\end{array}$ & $/ k_{\mathrm{rad}}\left[\mathrm{s}^{-1}\right]^{\mathrm{b}}$ & $K_{\text {obs }}\left[\mathrm{s}^{-1}\right]^{\mathrm{b}}$ & $\phi_{E u}^{E u c}$ & $\phi_{L}^{E u c}$ & $\eta_{\text {sens }}$ \\
\hline $\begin{array}{l}{\left[\mathrm{EuL} \mathbf{L}_{1}\right]^{-}} \\
\left(\mathrm{H}_{2} \mathrm{O}\right)\end{array}$ & 0.2 & 174 & 793 & 0.22 & 0.037 & 0.17 \\
\hline $\begin{array}{l}{\left[\mathrm{EuL} \mathbf{L}_{1}\right]^{-}} \\
\left(\mathrm{D}_{2} \mathrm{O}\right)\end{array}$ & 0.2 & 174 & 602 & 0.29 & 0.04 & 0.14 \\
\hline
\end{tabular}

Table 3. Calculated parameters for the determination of the efficiency of sensitization for [EuL1 $]^{-}$ complex in $\mathrm{H}_{2} \mathrm{O}$ and $\mathrm{D}_{2} \mathrm{O} .{ }^{\mathrm{a}}$ Estimated error $\pm 5 \%$. ${ }^{\mathrm{b}}$ Estimated error $\pm 10 \% .{ }^{\mathrm{c}}$ Estimated Error \pm $15 \%$.

Considering the potential interest of the $\mathrm{Yb}^{3+}$ complex for $\mathrm{UC}$ applications, variable temperature luminescence spectra and lifetimes were recorded in aqueous solution containing $10 \%$ glycerol 
(Figure 6 and Table 4). At low temperature, the spectrum is dominated by three intense emission bands at 980, 992 and $1010 \mathrm{~nm}$, with a shoulder on the low energy tail of the band at $992 \mathrm{~nm}$. Upon heating, the bands widened with the appearance of hot bands appearing at $c a .960 \mathrm{~nm} .{ }^{83,84}$ The $\mathrm{Yb}^{3+}$ excited state lifetime was determined to be mono-exponential at ambient temperature in the mixture containing glycerol, with a value slightly higher than in $\mathrm{H}_{2} \mathrm{O}$. However, when the temperature was decreased, a bi-exponential decay was observed with a short-lived component amounting to $c a .90 \%$ of the observed signal. The origin of these two $\mathrm{Yb}^{3+}$ sites is not perfectly clear and may arise from the presence of two isomeric forms, as it can be observed for other complexes like $[\operatorname{Ln}(\text { dota) })]^{85}$ for which the square antiprismatic (SAP) and twisted square antiprismatic (TSAP) forms could be observed with different spectroscopic properties. The presence of two species in equilibrium has also been reported for a closely related cyclam bispicolinate complex. ${ }^{86}$

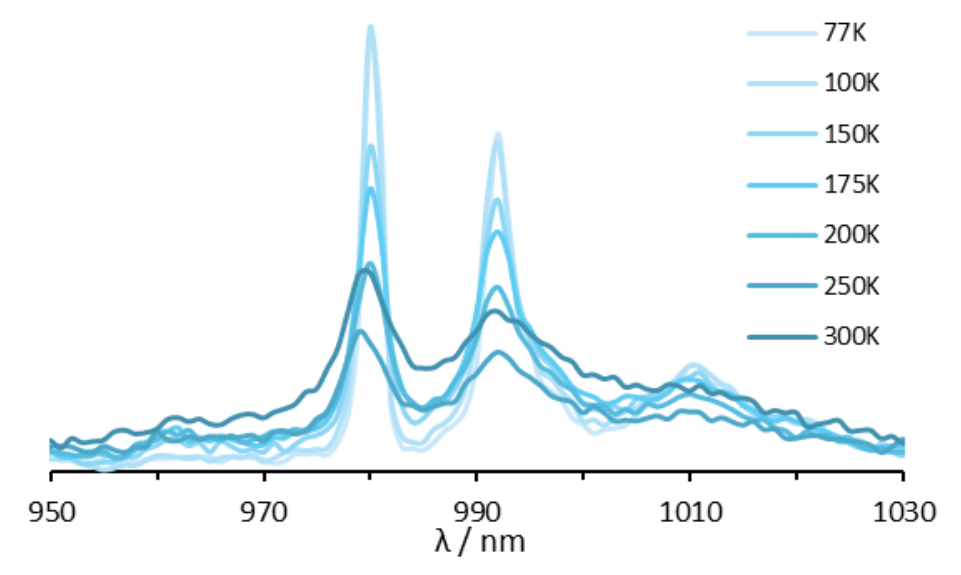

Figure 6. Evolution of the emission spectrum of $\left[\mathrm{YbL}_{1}\right]^{-}$by increase of the temperature. $\left[\mathrm{YbL}_{1}\right]^{-}$ $=2.5 \times 10^{-4} \mathrm{M}$ in $90 \% \mathrm{H}_{2} \mathrm{O}$ (tris. $\mathrm{HCl}$ buffer, $\mathrm{pH}=7.0,10 \mathrm{mM}$ ) and $10 \%$ glycerol.

\begin{tabular}{llllllll}
\hline $\mathrm{T}(\mathrm{K})$ & 77 & 100 & 150 & 175 & 200 & 250 & 300 \\
\hline
\end{tabular}




\begin{tabular}{llllllll}
\hline$\tau_{1}{ }^{\mathrm{a}}[\mu \mathrm{s}]$ & 10.8 & 9.3 & 8.1 & 7.4 & 6 & 3.7 & 3.6 \\
& $(86 \%)$ & $(86 \%)$ & $(92 \%)$ & $(94 \%)$ & $(96 \%)$ & $(92 \%)$ & $(100 \%)$ \\
$\tau_{2}{ }^{\mathrm{a}}[\mu \mathrm{s}]$ & 30.6 & 28.2 & 26.3 & 24.4 & 26.9 & 13.5 & \\
& $(14 \%)$ & $(14 \%)$ & $(8 \%)$ & $(6 \%)$ & $(4 \%)$ & $(8 \%)$ &
\end{tabular}

Table 4. Variation of $\left[\mathrm{YbL}_{1}\right]^{-}$lifetime with temperature. [YbL1] $]^{-}=2.47 \times 10^{-4} \mathrm{M}$ in $90 \% \mathrm{H}_{2} \mathrm{O}$ (tris. $\mathrm{HCl}$ buffer, $\mathrm{pH}=7.0,10 \mathrm{mM}$ ) and 10\% glycerol.

\section{Solution and Spectroscopic Studies of Heteropolynuclear Assemblies}

The promising structural and photophysical properties highlighted above, coupled with prior precedent of formation of polyatomic species in aqueous solutions, ${ }^{47,48,54,55}$ prompted us to investigate formation of heteropolynuclear lanthanide conjugates. Previous examples of 6phosphonated pyridyl complexes exhibiting $C_{3}$ symmetry and containing a convergent array of three phosphonate groups resulted in speciation of heteropolynuclear assemblies, primarily of 2:1 stoichiometry, with two complexes arranged around a central metal ion. It was anticipated that the differing $C_{2}$ symmetry of this new class of di-functionalised bisphosphonate complex [LnL $\mathbf{L}^{-}$ should facilitate the formation of higher order polynuclear complexes in solution. To study these properties, a ${ }^{1} \mathrm{H}$ NMR investigation $\left(298 \mathrm{~K}, \mathrm{D}_{2} \mathrm{O}, \mathrm{pD}=6.5-7.0\right)$ was conducted, in which the lutetium complex $[\mathrm{LuL}]_{1}{ }^{-}$was titrated with increasing amounts of $\mathrm{LuCl}_{3}$ (Figure 7). ${ }^{87}$ 


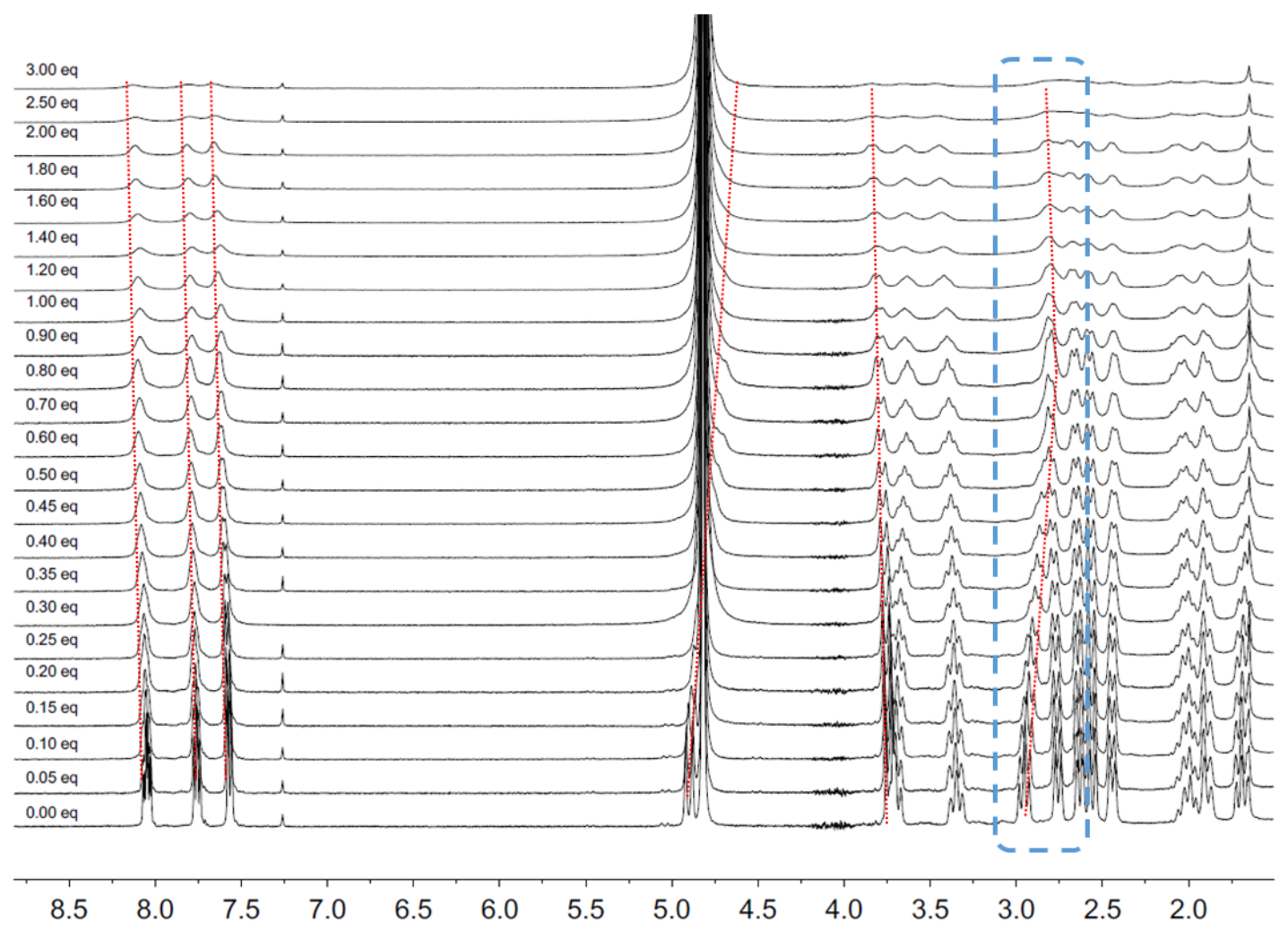

Figure 7. ${ }^{1} \mathrm{H}$ NMR $\left(400 \mathrm{MHz}, 298 \mathrm{~K}, \mathrm{D}_{2} \mathrm{O}, \mathrm{pD}=6.5-7.0\right)$ titrations of [LuL1] $]^{-}$in the presence of increasing amounts of $\mathrm{LuCl}_{3} \cdot 6 \mathrm{H}_{2} \mathrm{O}$

Upon addition of lutetium cations characteristic resonance shifts are observed between 0.0 eq. and 3.0 eq., with broadening occurring upon increasing amounts of $\mathrm{Lu}^{3+}$. Deshielding of the aromatic pyridyl resonances are apparent, consistent with coordination to a positively charged metal center. Large shifts are observed in the diastereotopic pyridyl methylenic resonances (4.90 ppm, 3.73 ppm; 0.0 eq. $\mathrm{LuCl}_{3}$ ) indicating reorganization of the complex geometry, characteristic of ligand guest association. Examination of the cyclam methylenic resonance at 2.95 ppm (0.0 eq. $\mathrm{LuCl}_{3}$ ) reveals atypical behaviour; initial upfield shifting followed by broadening and downfield shifting. Plotting $\Delta \delta$ as a function of equivalents of lutetium cations highlights this two-step behaviour (Figure 8). 


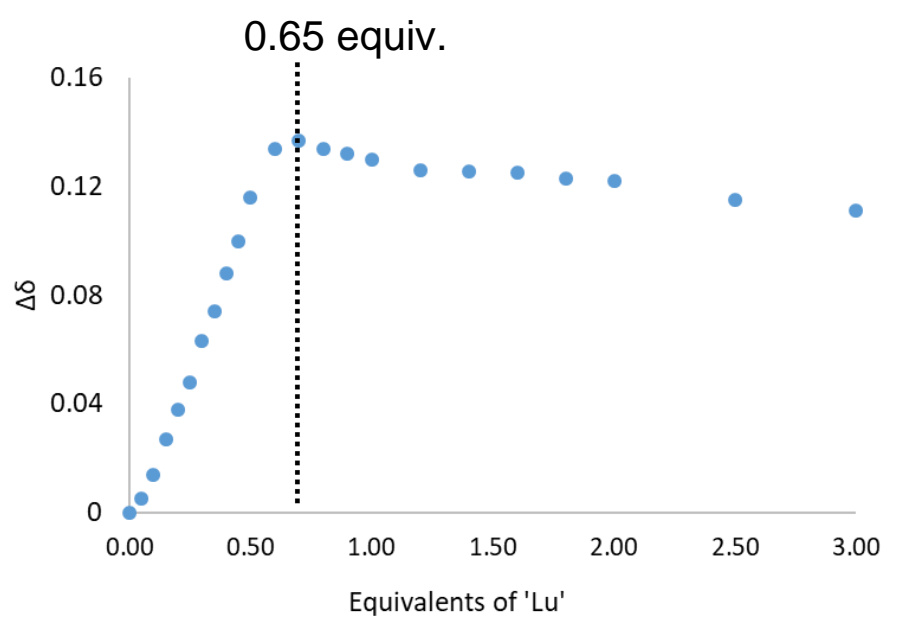

Figure 8. Plot of ${ }^{1} \mathrm{H}$ NMR shifts $\left(\Delta \delta\right.$; ppm) of the signal of $\mathrm{LuL}_{1}$ at $2.95 \mathrm{ppm}\left(0.0\right.$ eq. $\left.\mathrm{LuCl}_{3}\right) \mathrm{ppm}$ as a function of equivalents of added $\mathrm{LuCl}_{3} . \mathrm{H}_{2} \mathrm{O}\left(400 \mathrm{MHz}, 298 \mathrm{~K}, \mathrm{D}_{2} \mathrm{O}, \mathrm{pD}=6.5-7.0\right.$ (unbuffered))

The chemical shifts indicate a non-linear, slightly sigmoidal, upfield shift up to a maximum around 0.65 equivalents of lutetium cation, after which point the resonance moves back downfield. This suggests the prevalence of multiple species below 0.65 eq, the point around which a 3:2 host/guest stoichiometry is established and is then disrupted as the stoichiometry exceeds 0.65 eq. of $\mathrm{Lu}^{3+}$. Due to the presence of multiple host/guest species it was not possible to fit to a realistic binding model using the ${ }^{1} \mathrm{H}$ NMR data. To further probe supramolecular assembly with lanthanide guests, luminescent titrations were conducted in which the $[\mathrm{TbL}]^{-}$complex was titrated by $\mathrm{EuCl}_{3}$ in a buffered aqueous solution at $\mathrm{pH}=7$ (Figure 9) (Full titration data available in the Supplementary Information, Section 6.2.2). 

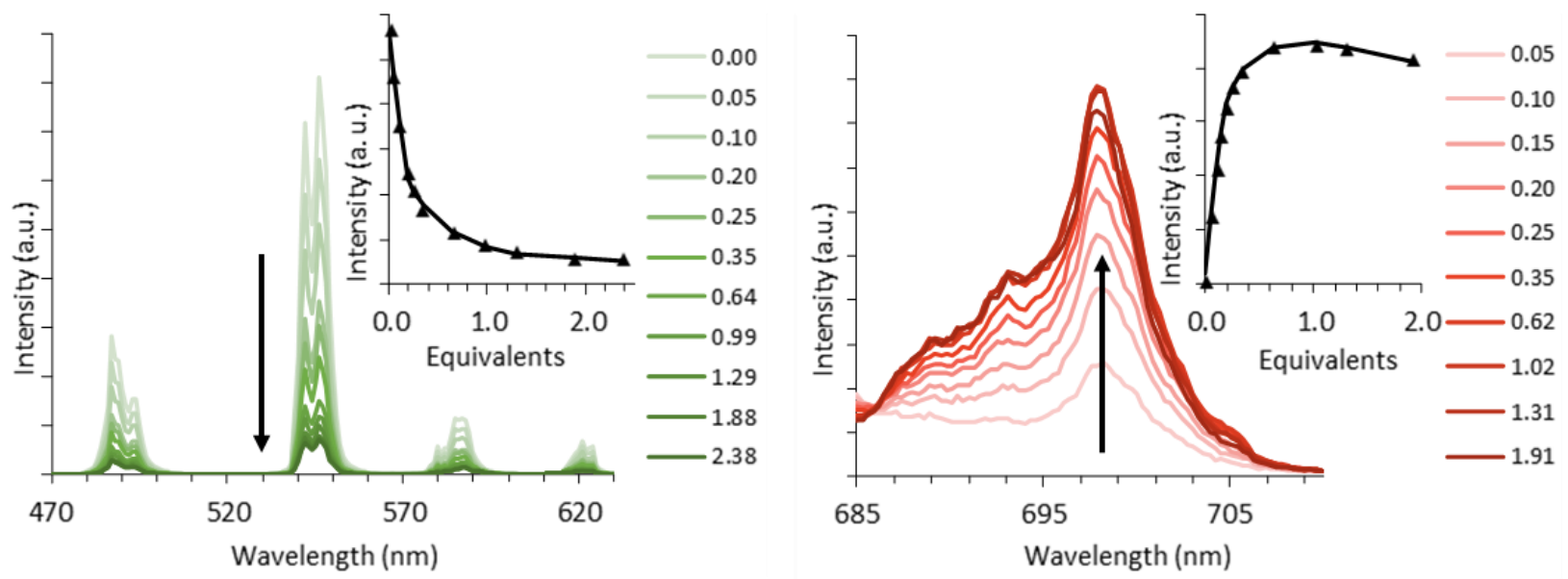

Figure 9. left: Evolution of the $\mathrm{Tb}^{3+}$ centered emission of $\left[\mathrm{Tb}_{1}\right]^{-}$upon titration with $\mathrm{EuCl}_{3} \cdot 6 \mathrm{H}_{2} \mathrm{O}$ $\left(\lambda_{\text {exc }}=278 \mathrm{~nm},\left[\mathrm{TbL}_{1}\right]^{-}=9.80 \times 10^{-5} \mathrm{M},\left[\mathrm{Eu}^{3+}\right]_{\text {stock }}=4.86 \times 10^{-4} \mathrm{M}\right.$, tris. $\mathrm{HCl} 10 \mathrm{mM}, \mathrm{pH}=7$, excitation slit widths $=$ emission slit widths $=0.5 \mathrm{~nm}$ ). Inset: Evolution of the emission intensity $\left(\lambda_{\mathrm{em}}=545 \mathrm{~nm}\right)$ and fit of the data according to the model (see text, data represented by points; fitted data represented by a solid black line). Right: Evolution of the $\mathrm{Eu}^{3+}$ centered emission in the NIR region (excitation slit width $=20 \mathrm{~nm}$; emission slit width $=0.3 \mathrm{~nm}$ ). Inset: Evolution of the intensity at $698 \mathrm{~nm}$ and fit of the data according to the model (see text, data represented by points; fitted data represented by a solid black line).

Upon addition of $\mathrm{Eu}^{3+}$ cations, we observed a dramatic decrease in the $\mathrm{Tb}^{3+}$ centered emission upon ligand excitation $\left(\lambda_{\mathrm{ex}}=272 \mathrm{~nm}\right)$, accompanied by the emergence of much weaker $\mathrm{Eu}^{3+}$ centered bands, which were obscured by the dominant $\mathrm{Tb}^{3+}$ emission. Monitoring of the spectra at lower energy $(c a .700 \mathrm{~nm})$ allowed unequivocal surveillance of only the $\mathrm{Eu}^{3+}$ based ${ }^{5} \mathrm{D}_{0} \rightarrow{ }^{7} \mathrm{~F}_{4}$ transition.

The diminution was particularly rapid up to $c a .0 .25$ eq. and slower thereafter. Considering the large differences in amplitude for the $\mathrm{Tb}$ and Eu emission signals, the NIR portion of the spectrum was monitored independently with larger emission slits. The factorial analysis embedded in the 
global analysis of the data with the Specfit software, ${ }^{88,89}$ indicated the formation of three new species $\left(\left[\left(\mathrm{TbL}_{1}\right)_{4} \mathrm{Eu}\right],\left(\left[\left(\mathrm{TbL}_{1}\right)_{3} \mathrm{Eu}\right]\right.\right.$, and $\left(\left[\left(\mathrm{TbL}_{1}\right)_{3} \mathrm{Eu}_{2}\right]\right)$ which could be conveniently fitted to the following model:

$$
\begin{array}{ll}
4\left[\mathrm{TbL}_{1}\right]+\mathrm{Eu} \leftrightarrow\left[\left(\mathrm{TbL}_{1}\right)_{4} \mathrm{Eu}\right] & \log \beta_{4: 1}=18.9(2) \\
3\left[\mathrm{TbL} L_{1}\right]+\mathrm{Eu} \leftrightarrow\left[\left(\mathrm{TbL}_{1}\right)_{3} \mathrm{Eu}\right] & \log \beta_{3: 1}=14.4(3) \\
3\left[\mathrm{TbL}_{1}\right]+2 \mathrm{Eu} \leftrightarrow\left[\left(\mathrm{TbL}_{1}\right)_{3} \mathrm{Eu}_{2}\right] & \log \beta_{3: 2}=19.5(3)
\end{array}
$$

The calculated speciation diagram obtained for the titration is displayed in Figure 10, while the reconstituted luminescence spectra of the species and the residuals of the fit are available in the Supplementary Information (Section 6.2.3). It is possible that the observation of emission of $\mathrm{Eu}^{3+}$ upon ligand excitation could be the result of $\mathrm{Tb}^{3+} / \mathrm{Eu}^{3+}$ exchange in the cavity of the ligand or via $\mathrm{Tb}^{3+}$ to $\mathrm{Eu}^{3+}$ energy transfer. A spectrofluorimetric titration of the $\left[\mathrm{EuL} \mathbf{L}_{1}\right]^{-}$complex by $\mathrm{TbCl}_{3} \cdot 6 \mathrm{H}_{2} \mathrm{O}$ revealed only minute variations of the $\mathrm{Eu}^{3+}$ centered emission, excluding the hypothesis of cation scrambling (Supplementary Information, Section 6.2.4). This indicates that under the experimental conditions the complexes $\left[\mathrm{Tb} \mathbf{L}_{1}\right]^{-}$are kinetically inert and the emergence of europium emission is ascribed to intermetallic $f$ - $f$ energy transfer.

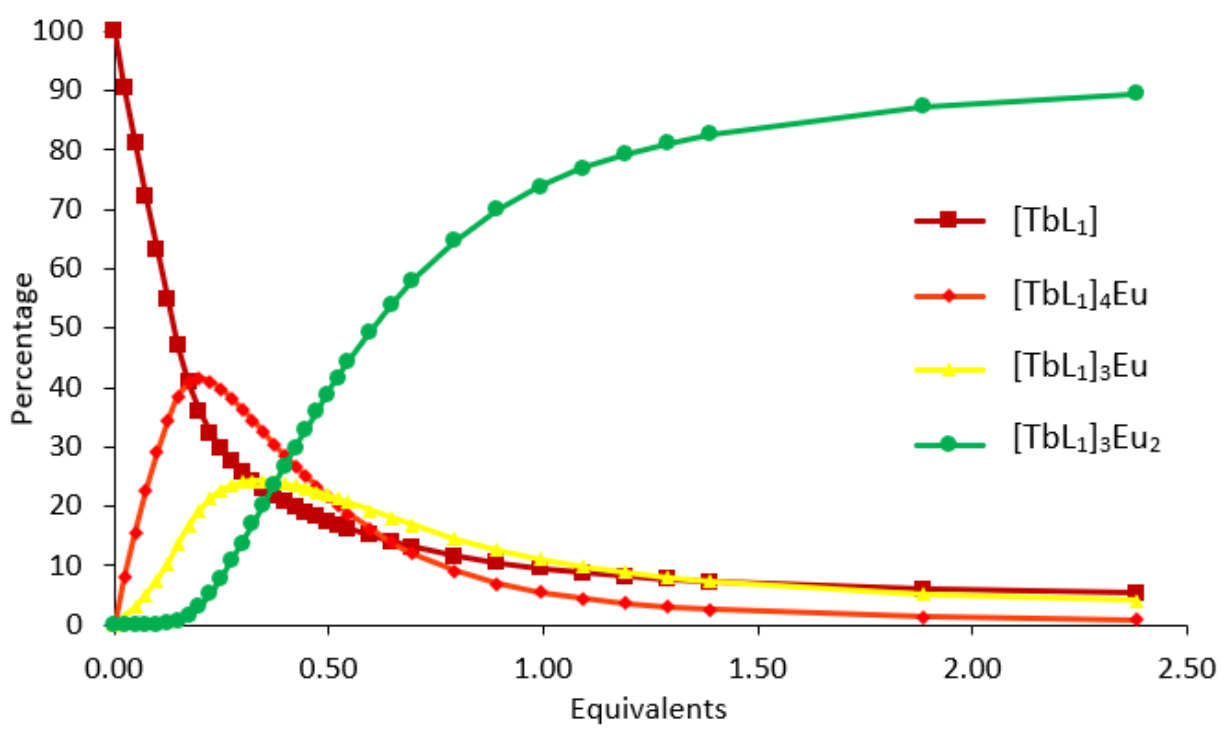


Figure 10. Evolution of the concentration of the species formed during the titration of $\left[\mathrm{Tb} \mathbf{L}_{1}\right]^{-}$by $\mathrm{EuCl}_{3}$.

The $\mathrm{Tb}^{3+}$ to $\mathrm{Eu}^{3+}$ energy transfer was investigated on the basis of luminescence decay measurements on both $\mathrm{Tb}^{3+}\left(\lambda_{\mathrm{em}}=545 \mathrm{~nm}\right)$ and $\mathrm{Eu}^{3+}\left(\lambda_{\mathrm{em}}=698 \mathrm{~nm}\right)$ emission upon ligand excitation. The full data set can be found in the Supplementary Information (Section 6.2.5). Surprisingly, the $\mathrm{Tb}^{3+}$ lifetime rapidly diminished at the beginning of the titration up to $c a .0 .2$ eq., but in all cases remained mono-exponential. This behavior was putatively attributed to a rapid exchange between free $\left[\mathrm{TbL}_{1}\right]^{-}$and the $\left[\left(\mathrm{Tb} \mathbf{L}_{1}\right)_{4} \mathrm{Eu}\right]$ species. After 0.2 eq. a bi-exponential behavior was observed, pointing to at least two distinct species, one with the lifetime of the free complex $\left[\mathrm{Tb} \mathbf{L}_{1}\right]^{-}(2.1 \mathrm{~ms})$. The most interesting aspect was the evolution of the $\mathrm{Eu}^{3+}$ centered intensity (Figure 11).

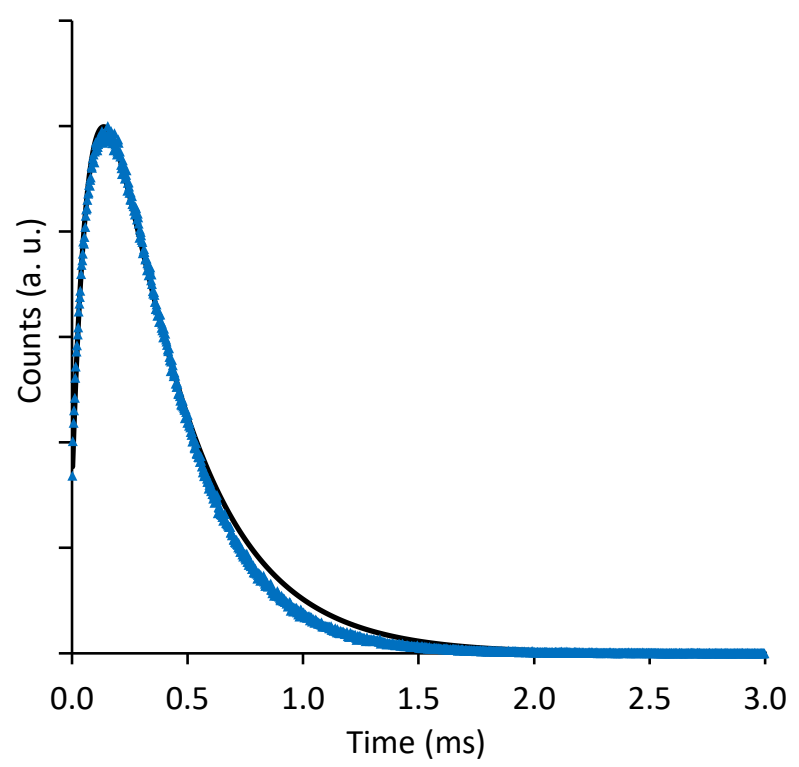

Figure 11. Time-dependent evolution of the Eu centered emission intensity $\left(\lambda_{\mathrm{em}}=700 \mathrm{~nm}\right)$ upon pulsed excitation of the ligand $\left(\lambda_{\mathrm{ex}}=278 \mathrm{~nm}\right)$ at $\mathrm{Eu}^{3+}: \mathrm{Tb}^{3+}$ ratio of 1.9:1 (blue points represent data points; continuous black line represents fitted data). 
Instead of displaying a conventional exponential decay, the intensity first rises before decaying. This behavior is typical of an energy transfer process with a rate constant of the same order of magnitude than the decay of the acceptor, ${ }^{11}$ and confirms that europium emission occurs as a consequence of energy transfer from a long-lived (i.e. terbium) emissive state. The differential equations describing the $\mathrm{Tb}^{3+}$ and $\mathrm{Eu}^{3+}$ excited state concentrations as a function of time are:

$$
\begin{aligned}
& \frac{d\left[E u^{*}\right]}{d t}=k_{E T}\left[T b^{*}\right]-\frac{1}{\tau_{E u}}\left[E u^{*}\right] \\
& \frac{d\left[T b^{*}\right]}{d t}=-k_{E T}\left[T b^{*}\right]-\frac{1}{\tau_{T b}}\left[T b^{*}\right]
\end{aligned}
$$

In which $k_{E T}$ represents the $\mathrm{Tb}^{3+}$ to $\mathrm{Eu}^{3+}$ energy transfer rate constant, $\tau_{E u}$ and $\tau_{T b}$ being the luminescence lifetime of $\mathrm{Eu}^{3+}$ and of $\mathrm{Tb}^{3+}$ in absence of $\mathrm{Eu}^{3+}$, respectively. The full resolution of the system is explained in the Supporting Information (Section 6.2.6). Finally, the evolution of the $\mathrm{Eu}^{3+}$ excited state is given by a sum of two exponential functions (equation (6)).

$$
[E u(t)]=\left(\left[E u_{0}\right]+\frac{[T b]_{0} \times k_{E T}}{\frac{1}{\tau_{T b}}+k_{E T}-\frac{1}{\tau_{E u}}}\right) \times \exp \left(\frac{-t}{\tau_{E u}}\right)-\frac{[T b]_{0}}{\frac{1}{\tau_{T b}}+k_{E T}-\frac{1}{\tau_{E u}}} \times \exp \left(-t \times\left(\frac{1}{\tau_{T b}}+k_{E T}\right)\right)
$$

Taking the lifetime of $\left[\mathrm{TbL}_{1}\right]^{-}$at $2.10 \mathrm{~ms}$, as found in absence of Eu, the fitting of the data (Figure 11) afforded values of $\tau_{E u}=336 \mu \mathrm{s}$ and $k_{E T}=1.12 \times 10^{4} \mathrm{~s}^{-1}$.

Considering that the energy transfer mechanism is based on a dipole-dipole Förster type mechanism, the energy transfer rate constant can be related to the Förster radius $R_{0}$, the distance at which half of the energy of the $\mathrm{Tb}$ donor is transferred to the Eu acceptor, and to the $\mathrm{Tb}-\mathrm{Eu}$ distance $r$ by the relation:

$$
k_{E T}=\frac{1}{\tau_{T b}}\left(\frac{R_{0}}{r}\right)^{6}
$$

From which one can estimate the $\mathrm{Tb}$ to Eu energy transfer efficiency, $\eta_{E T \text { : }}$ 


$$
\eta_{E T}=\frac{1}{1+\left(\frac{r}{R_{0}}\right)^{6}}=1-\frac{I_{T b E u}}{I_{T b}}=1-\frac{\tau_{T b E u}}{\tau_{T b}}
$$

The energy transfer process determined thereby amounts to $96 \%$ efficiency. In parallel, the efficiency was also calculated on the basis of the loss of intensity in presence of Eu, $I_{T b E u}$, compared to the intensity of the $[\mathrm{TbL}]^{-}$complex in absence of $\mathrm{Eu}, I_{T b}$. For this purpose, the calculated spectra obtained after the fitting procedure were used (See ESI, Section 6.2.3), leading to a value of 95\% for the energy transfer efficiency. The energy transfer efficiency can also be estimated from the shortening of the $\mathrm{Tb}$ lifetime in the presence of an Eu acceptor. At 1.9 eq., a short-lived component at $0.27 \mathrm{~ms}$ could be measured, thus giving an estimation of $\eta_{E T}$ to $87 \%$, in good agreement with other calculations. It is unfortunately not possible here to further extract the $\mathrm{Tb}^{3+}$ to $\mathrm{Eu}^{3+}$ distance with equation (7) as this would require the knowledge of the Eu absorption spectrum for the $f-f$ transition. Alternatively, values extracted from the literature for the $R_{0}$ of $\mathrm{Tb} / \mathrm{Eu}$ donor/acceptor pairs range from $4.1^{14}$ to more than $10 \AA,{ }^{15}$ allowing a rough estimation of the $\mathrm{Tb}$-Eu distance from 2.8 to $6.8 \AA$ A respectively for an average value of $91 \%$ of the energy transfer efficiency.

Regardless of the distance, the energy transfer from the $\left[\mathrm{Tb} \mathbf{L}_{1}\right]^{-}$complex to the $\mathrm{Eu}^{3+}$ cation was shown to be very efficient. Accordingly, we expected that similar titrations in which the $\left[\mathrm{YbL}_{1}\right]^{-}$complex is titrated by $\mathrm{TbCl}_{3}$ salts would present similarly high energy transfer efficiency with the possibility to observe an UC process. ${ }^{48,55}$ Unfortunately, this phenomenon could not be observed with this $\mathrm{Yb} / \mathrm{Tb}$ pair even when performing the titrations in $\mathrm{D}_{2} \mathrm{O}$. We postulate that the origins of this absence of upconverted emission is thus not a result of the energy transfer process efficiency, since the communication between the Ln-Ln dyads has been shown to be high for the $\mathrm{Eu} / \mathrm{Tb}$ pair. Rather we conclude that the lifetimes of the $\left[\mathrm{YbL}_{1}\right]^{-}$complex, which are diminished compared to our previously reported UC systems, are too short to facilitate formation of the $\mathrm{Tb}^{3+}$ excited state to any significant degree. 


\section{Conclusion}

We have developed an efficient synthesis for the synthesis of two related novel frameworks, $\mathbf{L}_{1} \mathrm{H}_{4}$ and $\mathbf{L}_{2} \mathrm{H}_{4}$ via a controlled methodology: protection, functionalization by alkylation of the remaining secondary amine functionalities, and deprotection of the Boc and ester protecting groups. The ligand system $\mathbf{L}_{\mathbf{1}}$ was found to be an effective chelator for a range of lanthanide cations $\left(\mathrm{Ln}^{3+}=\mathrm{Lu}, \mathrm{Eu}, \mathrm{Tb}, \mathrm{Yb}\right)$ while complexation studies with ligand $\mathbf{L}_{2}$ afforded only intractable mixtures of complexes. The solution and structural characteristics of the ligands have been investigated by NMR spectroscopy demonstrating $C_{2}$ symmetry in solution. Potentiometric studies revealed that the ligands generally retain the protonation properties of the unfunctionalised azamacrocyclic scaffold, cyclam, while exhibiting additional acido-basic phenomena attributable to the 6-pyridylphosphonic appendages, and broadly resemble previously reported picolinate derivatives.

The ligand $\mathbf{L}_{1}$ forms 1:1 metal/ligand species with octadentate geometry in aqueous solution, largely excluding the coordination of ancillary solvent molecules in the first coordination sphere of the complexes $(q=0.1-0.3)$. These simple 1:1 stoichiometric complexes LnL1 have been rigorously characterised by UV-vis. and luminescence spectroscopies. Furthermore, these 1:1 complexes have been used in the formation of heteropolynuclear assemblies, studied by both ${ }^{1} \mathrm{H}$ NMR investigations ([LuL1 $]^{-}$with $\left.\mathrm{Lu}^{3+}, \mathrm{D}_{2} \mathrm{O}, \mathrm{pD}=6.5-7.0\right)$ and spectrofluorometric titrations ([TbL1] $]^{-}$with $\mathrm{Eu}^{3+}, \mathrm{H}_{2} \mathrm{O}, \mathrm{pH}=7$ ). Global fitting of the emission experiments showed formation of $4: 1,3: 1$, and 3:2 heteropolynuclear assemblies, with highly efficient energy transfer ( $>90 \%$ efficiency, $\left[\mathrm{Tb} \mathbf{L}_{1}\right]_{\mathrm{x}} \mathrm{Eu}_{\mathrm{y}}$ ) occurring between the kinetically inert terbium complex and titrated europium cations. Despite high energy transfer efficiency, analogous spectrophotometric titrations 
with the $\left[\mathrm{YbL}_{1}\right]^{-/} / \mathrm{Tb}^{3+}$ dyad did not give observable UC energy transfer in heteropolynuclear assembles of these systems.

\section{Experimental Section}

\section{Materials and methods}

Commercial grade chemicals and solvents were used without further purification unless otherwise stated. Where anhydrous solvents were used, they were degassed with $\mathrm{N}_{2}$ and passed through an MBraun MPSP-800 column, except in the case of anhydrous THF, which was dried over $\mathrm{Na}$ /benzophenone, vacuum distilled, degassed and stored over $3 \AA$ molecular sieves. Molecular sieves were activated by heated at $200{ }^{\circ} \mathrm{C}$ under dynamic vacuum for 18 hours. Where degassed solvents were used, they were degassed via freeze-pump-thaw (3-cycles) and stored over an atmosphere of argon. De-ionised water dispensed from a Millipore Milli-Q purification system was used in all cases. NMR spectra were recorded with Bruker Avance 500 (500 MHz), Bruker Avance 400 (400 MHz), or Bruker AMX-3300 (300 MHz) spectrometers. All chemical shift $(\delta)$ values are given in parts per million and are referenced to the solvent. All coupling constants are quoted in $\mathrm{Hz}$. All ${ }^{31} \mathrm{P}$ and ${ }^{13} \mathrm{C}$ spectra are proton decoupled unless otherwise stated, all ${ }^{13} \mathrm{C}$ experiments were performed using the APT pulse sequence. In cases where solvent mixtures are used, the main solvent is used as the reference. In the case of the lanthanide titration experiments, these were performed in $\mathrm{D}_{2} \mathrm{O}$ and referenced internally using a $\mathrm{C}_{6} \mathrm{D}_{6}$ capillary. Where an apparent multiplet (e.g. app. t.) is quoted, $J_{\text {app }}$ is given. Accurate masses were determined to four decimal places; ESI-HRMS analyses were performed at ICOA, Orléans, France. Elemental analysis and mass spectrometry analysis were carried out by the Service Commun d'Analyses of the University of Strasbourg. UV-vis. absorption spectra were recorded on a Specord spectrometer from Jena Analytics. Molar extinction coefficients were measured twice and given as a mean value. Steady 
state emission spectra were recorded on a Horiba Jobin Yvon Fluorolog working with a continuous $450 \mathrm{~W}$ Xe Lamp and an Edinburgh Instrument FLP920 spectrometer working with a continuous 450 W Xe Lamp and a red sensitive R928 photomultiplier from Hamamatsu in Pelletier housing for visible detection (230 to $900 \mathrm{~nm}$ ) or a Hamamatsu R5 509-72 photomultiplier for the Vis-NIR part. The Fluorolog was used for the terbium and europium studies and the Edinburgh for the ytterbium study. All spectra were corrected for the instrumental functions. For emission spectra upon UV excitation, a $330 \mathrm{~nm}$ cut-off filter was used to eliminate second order artefacts. Phosphorescence lifetimes were measured on the same instruments working in the Multi-Channel Spectroscopy (MCS) mode, using a Xenon flash lamp as the excitation source. For short millisecond lifetimes, the intensity decay was corrected from the lamp intensity decay profile using a scattering solution of Ludox in water. Luminescence quantum yields were measured according to conventional procedures, ${ }^{90}$ with optically diluted solutions (optical density $<0.05$ ), using $\left[\mathrm{Ru}(\text { bipy })_{3} \mathrm{Cl}_{2}\right]$ in water $(\Phi=0.04)^{76}$ as reference for Eu, a bipyridine $\mathrm{Tb}$ complex, [TbL $\left.(\mathrm{H} 2 \mathrm{O})\right]$ in water $(\Phi=0.81)^{77}$ as reference for $\mathrm{Tb}$, and cardiogreen (IR125) in $\mathrm{MeOH}(\Phi=0.078)$ for $\mathrm{Yb}^{78}$ The errors are estimated to be $10 \%$ on the lifetimes and $15 \%$ on the luminescence quantum yields. Hydrations numbers, $q$, were obtained using equation of Beeby et al. ${ }^{74}$ Absorption and spectrofluorimetric titration experiments were conducted according to previously published protocols. ${ }^{91}$

$$
\text { di-tert-butyl 1,4,8,11-tetraazacyclotetradecane-1,8-dicarboxylate, }{ }^{92} \quad 1,4,8,11 \text { - }
$$

tetraazabicyclo[6.6.2] hexadecane (cb-cyclam), ${ }^{93}$ and diethyl (6-(chloromethyl)pyridin-2yl)phosphonate ${ }^{54}$ were synthesised as previously described.

\section{Potentiometry}


Starting Materials and Solvents. Distilled water was purified by passing it through a mixed bed of ion-exchanger (BIOBLOCK Scientific R3-83002, M3-83006) and activated carbon (BIOBLOCK Scientific ORC-83005) and was de-oxygenated by $\mathrm{CO}_{2}-$ and $\mathrm{O}_{2}$-free argon (SiGMA Oxiclear cartridge) just before use. The stock solutions were prepared by weighing solid products on an AG 245 MetTLER TOLEDO analytical balance (precision $0.01 \mathrm{mg}$ ). The ionic strength was maintained at 0.1 M with sodium chloride (NaCl, CARLO-ERBA-SDS PHAR. EUR. 99-100.5\%), and all measurements were carried out at $25.0(2){ }^{\circ} \mathrm{C}$. The ytterbium stock solutions $\left(4.60 \times 10^{-2} \mathrm{M}\right)$ were freshly prepared by dissolution of appropriate amounts of the corresponding solid perchlorate salts in water. Ytterbium chloride $\left(\mathrm{YbCl}_{3} .6 \mathrm{H}_{2} \mathrm{O}\right.$, SIGMA, 99.99\%) is a commercial product, which was used without further purification. The metal contents of the solutions were determined according to the classical colorimetric titrations. ${ }^{94}$

Potentiometric Titrations. The potentiometric titrations of ligands $\mathbf{L}_{1}\left(1.57 \times 10^{-3} \mathrm{M}\right), \mathbf{L}_{2}(1.70$ $\left.\times 10^{-3} \mathrm{M}\right)$ and the ytterbium complex with $\mathbf{L}_{\mathbf{1}}\left([\mathrm{Yb}]_{\mathrm{tot}} /\left[\mathbf{L}_{\mathbf{1}}\right]_{\mathrm{tot}}=1.0\right)$ were performed using an automatic titrator system 794 Basic Titrino (METROHM) with a combined glass electrode (Metrohm 6.0234.500, Long Life) filled with $0.1 \mathrm{M} \mathrm{NaCl}$ in water and connected to a microcomputer (TIAMO light 1.2 program for the acquisition of the potentiometric data). The combined glass electrode was calibrated as a hydrogen concentration probe by titrating known amounts of hydrochloric acid $\left(\sim 1.72 \times 10^{-1} \mathrm{M}\right.$ from HCl, SigMA-ALDRICH, puriss pa, >37 \%) with $\mathrm{CO}_{2}$-free sodium hydroxide solution $\left(\sim 9.8 \times 10^{-2}\right.$ to $1.23 \times 10^{-1} \mathrm{M}$ from $\mathrm{NaOH}, \mathrm{BDH}$, AnalaR, 98\%). The $\mathrm{HCl}$ and $\mathrm{NaOH}$ solutions were freshly prepared just before use and titrated with sodium tetraborate decahydrate $\left(\mathrm{B}_{4} \mathrm{Na}_{2} \mathrm{O}_{7} .10 \mathrm{H}_{2} \mathrm{O}\right.$, FLUKA, puriss, p.a., $\left.>99.5 \%\right)$ and potassium hydrogen phthalate $\left(\mathrm{C}_{8} \mathrm{H}_{5} \mathrm{KO}_{3}\right.$, FLUKA, puriss, p.a., > 99.5\%), respectively, with methyl orange (RAL) and phenolphthalein (PROLABO, purum) used as colorimetric indicators. The temperature of the 
titration cell was maintained at $25.0 \pm 0.2{ }^{\circ} \mathrm{C}$ with the help of a LAUDA E200 thermostat. The GLEE program ${ }^{95}$ was applied for the glass electrode calibration (standard electrode potential $\mathrm{E}_{0} / \mathrm{mV}$ and slope of the electrode $\left./ \mathrm{mV} \mathrm{pH}^{-1}\right)$ and to check carbonate levels of the $\mathrm{NaOH}$ solutions used $(<5$ $\%$ ). The potentiometric data of $\mathbf{L}_{1}$ and its ytterbium complex as well as those of $\mathbf{L}_{2}$ (about 300 points collected over the $\mathrm{pH}$ range $2.5-11.5$ ) were refined with the HYPERQUAD $2000^{96}$ program which uses non-linear least-squares methods. ${ }^{97}$ Potentiometric data points were weighted by a formula allowing greater $\mathrm{pH}$ errors in the region of an end-point than elsewhere. The weighting factor $W_{\mathrm{i}}$ is defined as the reciprocal of the estimated variance of measurements: $W_{\mathrm{i}}=1 / \sigma_{\mathrm{i}}{ }^{2}=1 /\left[\sigma_{\mathrm{E}}{ }^{2}\right.$ $\left.+(\delta \mathrm{E} / \delta \mathrm{V})^{2} \sigma \mathrm{v}^{2}\right]$ where $\sigma \mathrm{E}^{2}$ and $\sigma \mathrm{v}^{2}$ are the estimated variances of the potential and volume readings, respectively. The constants were refined by minimizing the error-square sum, $U$, of the potentials: $U=\sum^{N} W_{i}\left(E_{\text {obis }}-E_{\text {cati }}\right)^{2}$. At least three potentiometric titrations were treated as single sets, for each system. The quality of fit was judged by the values of the sample standard deviation, $S$, and the goodness of fit, $\chi^{2}$, (Pearson's test). At $\sigma_{\mathrm{E}}=0.1 \mathrm{mV}\left(0.023 \sigma_{\mathrm{pH}}\right)$ and $\sigma_{\mathrm{V}}=0.002 \mathrm{~mL}$, the values of $S$ in different sets of titrations were close to 1 . The scatter of residuals versus $\mathrm{pH}$ was reasonably random, without any significant systematic trends, thus indicating a good fit of the experimental data. The successive protonation constants were calculated from the cumulative constants determined with the program. The uncertainties in the $\log K$ values correspond to the added standard deviations in the cumulative constants.

Spectrophotometric Titrations vs. pH. To validate and assign the protonation sites, spectrophotometric titrations of $\mathbf{L}_{1}$ and $\mathbf{L}_{2}$ were then carried out. An aliquot of $40 \mathrm{~mL}$ of solutions containing $\mathbf{L}_{1}\left(1.08 \times 10^{-4} \mathrm{M}\right)$ or $\mathbf{L}_{2}\left(8.88 \times 10^{-5} \mathrm{M}\right)$ were introduced in a jacketed cell (METROHM) maintained at $25.0(2){ }^{\circ} \mathrm{C}$ (LAUDA E200). The free hydrogen ion concentration was measured with a combined glass electrode (Metrohm 6.0234.500, Long Life) and an automatic titrator system 
794 Basic Titrino (MetroHm). The $\mathrm{Ag} / \mathrm{AgCl}$ reference glass electrode was filled with $\mathrm{NaCl}(0.1$ M, CARLO-ERBA-SDS Phar. EUR. 99-100.5\%) and was calibrated as a hydrogen concentration probe as described above. The initial $\mathrm{pH}$ was adjusted to $~ 2.4-2.9$ with $\mathrm{HCl}$ (SIGMA-ALDRICH, puriss pa, $>37 \%$ ) and the titrations of the ligands ( $\mathbf{L}_{1}: 2.45<\mathrm{pH}<10.77$ and $\mathbf{L}_{2}: 2.92<\mathrm{pH}<$ 10.81) were then carried out by automatic addition of known volumes of $\mathrm{NaOH}$ solutions (BDH, AnalaR). After each addition (i.e. the volume and thus the $\mathrm{pH}$ variations during the absorption versus $\mathrm{pH}$ titrations were automatically adjusted by the potentiometric system according to the change in the potentiometric signal of the solution; the DET method - Dynamic Potential Titration - of the Tiamo program was used here with a measuring point density of 3), an absorption spectrum was repeatedly recorded using a Varian CARY 50 spectrophotometer fitted with Hellma optical fibres (Hellma, 041.002-UV) and an immersion probe made of quartz suprasil (Hellma, 661.500QX) and interfaced (Cetrib) with the potentiometric unit.

Analysis and Processing of the Spectroscopic Data. The spectrophotometric data were analysed with SPECFIT $88,89,98$ program which adjusts the absorptivities and the stability constants of the species formed at equilibrium. SPECFIT uses factor analysis to reduce the absorbance matrix and to extract the eigenvalues prior to the multiwavelength fit of the reduced data set according to the Marquardt algorithm..$^{99,100}$

\section{Synthesis of 1}

di-tert-butyl 1,4,8,11-tetraazacyclotetradecane-1,8-dicarboxylate ( $0.520 \mathrm{~g}, 1.29 \mathrm{mmol}, 1.0 \mathrm{eq}$,$) ,$ diethyl (6-(chloromethyl)pyridin-2-yl)phosphonate (0.728 g, $2.73 \mathrm{mmol}, 2.1$ eq,) and $\mathrm{K}_{2} \mathrm{CO}_{3}$ (0.376 g, $2.73 \mathrm{mmol}, 2.1$ eq.) were dissolved in anhydrous $\mathrm{MeCN}(20 \mathrm{~mL})$ under an $\mathrm{N}_{2}$ atmosphere. The reaction was stirred at $40{ }^{\circ} \mathrm{C}$ for 5 days. The reaction was filtered and the solvent removed in vacuo. The crude material was purified by column chromatography $\left(\mathrm{SiO}_{2}\right.$; 
$\left.\mathrm{CH}_{2} \mathrm{Cl}_{2} / \mathrm{MeOH} ; 100: 0 \rightarrow 97: 3\right)$ to obtain 1 as an off-white foamy solid $(0.580 \mathrm{~g}, 0.68 \mathrm{mmol}, 52 \%)$.

${ }^{1} \mathrm{H}$ NMR (400 MHz, $\left.298 \mathrm{~K}, \mathrm{CDCl}_{3}\right) 7.80\left(\mathrm{t},{ }^{3} \mathrm{JHH}_{\mathrm{HH}}=7.1,2 \mathrm{H}, \mathrm{PyH}\right), 7.71(\mathrm{~s}, 2 \mathrm{H}, \mathrm{PyH}), 7.58\left(\mathrm{~d},{ }^{3} J_{\mathrm{HH}}\right.$ $=7.9,2 \mathrm{H}), 4.30-4.13\left(\mathrm{~m}, 8 \mathrm{H}, \mathrm{POC}_{2} \mathrm{CH}_{3}\right), 3.82\left(\mathrm{~s}, 4 \mathrm{H}, \mathrm{NCH}_{2} \mathrm{Py}\right), 3.46-3.26\left(\mathrm{~m}, 8 \mathrm{H}, \mathrm{NCH}_{2}\right)$, 2.57 (br. s, 8H, $\mathrm{NCH}_{2}$ ), 1.79 (br. s, $4 \mathrm{H}, \mathrm{NCH}_{2} \mathrm{C}_{2}$ ), $1.46-1.24$ (m, 30H, $\mathrm{POCH}_{2} \underline{\mathrm{C}}_{3}+{ }^{\mathrm{t}} \mathrm{Bu}$ ); ${ }^{13} \mathrm{C}$ NMR (76 MHz, $\left.298 \mathrm{~K}, \mathrm{CDCl}_{3}\right) 161.21\left(\mathrm{~d},{ }^{3} J_{\mathrm{PC}}=22.4, \mathrm{Py}\right), 155.65\left(\mathrm{~s}, \mathrm{NCO}_{2}{ }^{\mathrm{t}} \mathrm{Bu}\right), 152.07\left(\mathrm{~d},{ }^{1} J_{\mathrm{PC}}\right.$ $=227.4, \mathrm{Py}), 136.32(\mathrm{~s} \mathrm{Py}), 126.40\left(\mathrm{~d},{ }^{2} J_{\mathrm{PC}}=25.1, \mathrm{Py}\right), 124.91(\mathrm{~s}, \mathrm{Py}), 79.42\left(\mathrm{~s}, \mathrm{NCH}_{2} \mathrm{Py}\right), 62.96$ $\left(\mathrm{d},{ }^{2} J_{\mathrm{PC}}=5.7, \mathrm{POCH}_{2} \mathrm{CH}_{3}\right), 61.38\left(\mathrm{~s}, \underline{\mathrm{C}}\left(\mathrm{CH}_{3}\right)_{3}\right), 53.73\left(\mathrm{~s}, \mathrm{NCH}_{2}\right), 52.11\left(\mathrm{~s}, \mathrm{NCH}_{2}\right), 28.44\left(\mathrm{~s},{ }^{\mathrm{t}} \mathrm{Bu}\right)$, $16.42\left(\mathrm{~d},{ }^{3} \mathrm{JC}_{\mathrm{PC}}=6.2, \mathrm{POCH}_{2} \underline{\mathrm{CH}}_{3}\right) ;{ }^{31} \mathrm{P}$ NMR $\left(162 \mathrm{MHz}, 298 \mathrm{~K}, \mathrm{CDCl}_{3}\right) 11.8(\mathrm{~s}) ;$ ESI-HRMS m/z calcd. for $\left[\mathrm{C}_{30} \mathrm{H}_{52} \mathrm{~N}_{6} \mathrm{O}_{6} \mathrm{P}_{2}+2 \mathrm{H}\right]^{+} 328.1785$ found 328.1784 (Boc protecting groups cleaved under MS experiment conditions).

\section{Synthesis of te2pyp $\left(\mathrm{L}_{1} \mathrm{H}_{4}\right)$}

$1(388 \mathrm{mg}, 0.453 \mathrm{mmol})$ was dissolved in $6 \mathrm{M} \mathrm{HCl}_{(\mathrm{aq})}(20 \mathrm{~mL})$ and heated at $110^{\circ} \mathrm{C}$ for 48 hours. The reaction mixture was cooled and the solvent removed in vacuo. The compound was purified by automated column chromatography $\left(\mathrm{C}_{18} ; \mathrm{H}_{2} \mathrm{O} / \mathrm{MeCN} ; 100: 0 \rightarrow 80: 20\right)$ to obtain $\mathrm{L}_{1} \mathrm{H}_{2} .4 \mathrm{HCl}$ as a white solid (235 mg, $0.341 \mathrm{mmol}, 75 \%) .{ }^{1} \mathrm{H}$ NMR (400 MHz, $\left.298 \mathrm{~K}, \mathrm{D}_{2} \mathrm{O}, \mathrm{pD}=10\right) 7.52\left(\mathrm{t},{ }^{3} J_{\mathrm{HH}}\right.$ $=6.8,2 \mathrm{H}, \mathrm{PyH}), 7.43\left(\mathrm{td},{ }^{3} \mathrm{JHH}_{\mathrm{HH}}=7.8,4.0,2 \mathrm{H}, \mathrm{PyH}\right), 6.87\left(\mathrm{~d},{ }^{3} J_{\mathrm{HH}}=7.8,2 \mathrm{H}, \mathrm{PyH}\right), 3.78(\mathrm{~s}, 4 \mathrm{H}$, $\left.\mathrm{NCH}_{2} \mathrm{Py}\right), 3.21\left(\mathrm{t},{ }^{3} J_{\mathrm{HH}}=5.4,8 \mathrm{H}, \mathrm{NCH}_{2}\right), 2.98\left(\mathrm{t},{ }^{3} J_{\mathrm{HH}}=5.3,4 \mathrm{H}, \mathrm{NCH}_{2}\right), 2.74\left(\mathrm{t},{ }^{3} J_{\mathrm{HH}}=4.9,4 \mathrm{H}\right.$, $\mathrm{NCH}_{2}$ ), 1.80 (app. p, $J_{\text {app }}=5.3,4 \mathrm{H}, \mathrm{NCH}_{2} \mathrm{C}_{2}$ ); ${ }^{13} \mathrm{C} \mathrm{NMR}\left(76 \mathrm{MHz}, 298 \mathrm{~K}, \mathrm{D}_{2} \mathrm{O}, \mathrm{pD}=10\right) 162.86$ $\left(\mathrm{d},{ }^{1} J_{\mathrm{PC}}=195.8, \mathrm{Py}\right), 158.34\left(\mathrm{~d},{ }^{3} J_{\mathrm{PC}}=17.8, \mathrm{Py}\right), 137.68\left(\mathrm{~d},{ }^{3} J_{\mathrm{PC}}=10.1, \mathrm{Py}\right), 125.10\left(\mathrm{~d},{ }^{2} J_{\mathrm{PC}}=\right.$ 20.8, Py), $123.72\left(\mathrm{~d},{ }^{4} J_{\mathrm{PC}}=3.4, \mathrm{Py}\right), 62.17\left(\mathrm{~s}, \mathrm{NCH}_{2} \mathrm{Py}\right), 57.53\left(\mathrm{~s}, \mathrm{NCH}_{2}\right), 54.38\left(\mathrm{~s}, \mathrm{NCH}_{2}\right), 50.00$ (s, $\mathrm{NCH}_{2}$ ), $47.83\left(\mathrm{~s}, \mathrm{NCH}_{2}\right), 22.91\left(\mathrm{~s}, \mathrm{NCH}_{2} \mathrm{CH}_{2}\right) ;{ }^{31} \mathrm{P} \mathrm{NMR}\left(162 \mathrm{MHz}, 298 \mathrm{~K}, \mathrm{D}_{2} \mathrm{O}\right) 0.4$ (s); ESIHRMS m/z calcd. for $\left[\mathrm{C}_{22} \mathrm{H}_{36} \mathrm{~N}_{6} \mathrm{O}_{6} \mathrm{P}_{2}+\mathrm{H}\right]^{+} 543.2244$ found 543.2247; UV/vis. (Tris $\mathrm{Buffer}_{(\mathrm{aq})} 0.1$ 
M) $\lambda_{\max }\left(\varepsilon_{\max }\right) ; 229$ (4300), 285 (4500); Anal. Calcd for $\mathrm{C}_{22} \mathrm{H}_{40} \mathrm{Cl}_{4} \mathrm{~N}_{6} \mathrm{O}_{6} \mathrm{P}_{2}\left(688.34 \mathrm{~g} \mathrm{~mol}^{-1}\right)$ : C, 38.39; H, 5.86; N, 12.21. Found: C, 38.39; H, 5.98; N, 12.21.

\section{Synthesis of 2}

1,4,8,11-tetraazabicyclo[6.6.2]hexadecane (cb-cyclam) (503 mg, $2.22 \mathrm{mmol}, 1.0 \mathrm{eq}$,), diethyl (6-(chloromethyl)pyridin-2-yl)phosphonate (1.20 g, $4.55 \mathrm{mmol}, 2.05 \mathrm{eq}$ ), $\mathrm{K}_{2} \mathrm{CO}_{3}$ (1.531 g, 11.1 mmol, 5.0 eq, ) and $\mathrm{NaI}(0.681 \mathrm{~g}, 4.55 \mathrm{mmol}, 2.05 \mathrm{eq}$,) were dissolved in anhydrous MeCN (50 $\mathrm{mL}$ ) under an $\mathrm{N}_{2}$ atmosphere. The reaction was stirred at $40{ }^{\circ} \mathrm{C}$ for 3 days. The reaction was filtered and the solvent removed in vacuo. The crude material was purified by column chromatography $\left(\mathrm{SiO}_{2} ; \mathrm{CH}_{2} \mathrm{Cl}_{2} / \mathrm{MeOH} ; 100: 0 \rightarrow 95: 5\right)$ to obtain 2 as an off-white foamy solid (1.185 g, $1.74 \mathrm{mmol}$, 78\%). ${ }^{1} \mathrm{H}$ NMR (400 MHz, $\left.298 \mathrm{~K}, \mathrm{CDCl}_{3}\right) 10.82$ (s, 1H, NH), 7.86 - 7.81 (m, 4H, PyH), $7.63-$

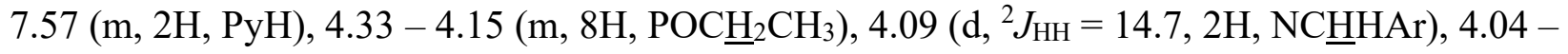
$3.83\left(\mathrm{~m}, 4 \mathrm{H}, \mathrm{NCH} \underline{\mathrm{HAr}}+\mathrm{NCH}_{2}\right), 3.50-3.03\left(\mathrm{~m}, 12 \mathrm{H}, \mathrm{NCH}_{2}\right), 3.03-2.89\left(\mathrm{~m}, 4 \mathrm{H}, \mathrm{NCH}_{2}\right), 2.74$ $\left.-2.65 \mathrm{~m}, 2 \mathrm{H}, \mathrm{NCH}_{2}\right), 1.97-1.65\left(\mathrm{~m}, 4 \mathrm{H}, \mathrm{NCH}_{2} \underline{\mathrm{C}}_{2}\right), 1.39$ (app. $\mathrm{td},{ }^{2} J_{\mathrm{HH}}=7.1, J=2.2,12 \mathrm{H}$, $\left.\mathrm{POCH}_{2} \underline{\mathrm{CH}}_{3}\right) ;{ }^{13} \mathrm{C} \mathrm{NMR}\left(76 \mathrm{MHz}, 298 \mathrm{~K}, \mathrm{CDCl}_{3}\right) 158.20\left(\mathrm{~d},{ }^{3} J_{\mathrm{PC}}=22.7, \mathrm{Py}\right), 151.77\left(\mathrm{~d},{ }^{1} J_{\mathrm{PC}}=\right.$ 228.1, Py), $136.43\left(\mathrm{~d},{ }^{3} J_{\mathrm{PC}}=13.2\right.$, Py), $126.41(\mathrm{~s}, \mathrm{Py}), 126.15\left(\mathrm{~d},{ }^{2} J_{\mathrm{PC}}=25.2, \mathrm{Py}\right), 62.56\left(\mathrm{~d},{ }^{2} J_{\mathrm{PC}}=\right.$ 6.3, $\left.\mathrm{POCH}_{2} \mathrm{CH}_{3}\right), 57.81\left(\mathrm{~s}, \mathrm{NCH}_{2}\right), 56.88\left(\mathrm{~s}, \mathrm{NCH}_{2}\right), 54.12\left(\mathrm{~s}, \mathrm{NCH}_{2}\right), 52.61\left(\mathrm{~s}, \mathrm{NCH}_{2}\right), 52.02(\mathrm{~s}$, $\left.\mathrm{NCH}_{2}\right), 51.14\left(\mathrm{~s}, \mathrm{NCH}_{2}\right), 24.02\left(\mathrm{~s}, \mathrm{NCH}_{2} \underline{\mathrm{CH}}_{2}\right), 16.19\left(\mathrm{~d},{ }^{3} \mathrm{JC}_{\mathrm{PC}}=5.2, \mathrm{POCH}_{2} \mathrm{CH}_{3}\right) ;{ }^{31} \mathrm{P}$ NMR $(162$ $\left.\mathrm{MHz}, 298 \mathrm{~K}, \mathrm{CDCl}_{3}\right) 11.2(\mathrm{~s})$; ESI-HRMS m/z calcd. for $\left[\mathrm{C}_{32} \mathrm{H}_{54} \mathrm{~N}_{6} \mathrm{O}_{6} \mathrm{P}_{2}+\mathrm{H}\right]^{+} 681.3653$ found 681.3648 .

\section{Synthesis of cb-te2pp ( $\left.\mathrm{L}_{2} \mathrm{H}_{4}\right)$}

$2(1.185 \mathrm{~g}, 1.74 \mathrm{mmol})$ was dissolved in $6 \mathrm{M} \mathrm{HCl}_{(\mathrm{aq})}(20 \mathrm{~mL})$ and heated at $110^{\circ} \mathrm{C}$ for 48 hours. The reaction mixture was cooled and the solvent removed in vacuo. The crude material was dissolved in a minimum of $\mathrm{H}_{2} \mathrm{O}(c a .5 \mathrm{~mL})$ and layered with acetone $(c a .100 \mathrm{~mL})$ to obtain 
$\mathrm{L}_{2} \mathrm{H}_{2} .1 \mathrm{HCl} .4 \mathrm{H}_{2} \mathrm{O}$ as a white crystalline solid (693 mg, $\left.1.02 \mathrm{mmol}, 59 \%\right) .{ }^{1} \mathrm{H}$ NMR (400 MHz, 298 $\left.\mathrm{K}, \mathrm{D}_{2} \mathrm{O}\right) 7.64\left(\mathrm{t},{ }^{3} J_{\mathrm{HH}}=7.2,2 \mathrm{H}, \mathrm{PyH}\right), 7.47\left(\mathrm{td},{ }^{3} J_{\mathrm{HH}}=7.8,{ }^{4} J_{\mathrm{HH}}=4.5,2 \mathrm{H}, \mathrm{PyH}\right), 6.77\left(\mathrm{dd},{ }^{3} J_{\mathrm{HH}}=\right.$ $\left.7.9,{ }^{4} J_{\mathrm{HH}}=1.9,2 \mathrm{H}, \mathrm{PyH}\right), 5.18\left(\mathrm{~d},{ }^{2} J_{\mathrm{HH}}=17.0,2 \mathrm{H}, \mathrm{NC} \underline{\mathrm{HHAr}}\right), 4.40-4.24\left(\mathrm{~m}, 2 \mathrm{H}, \mathrm{NCH}_{2}\right), 3.99$ $-3.72\left(\mathrm{~m}, 8 \mathrm{H}, \mathrm{NCH}_{2}+\mathrm{NCH} \underline{\mathrm{H} A r}\right), 3.58-3.46(\mathrm{~m}, 2 \mathrm{H}), 3.22-3.09\left(\mathrm{~m}, 2 \mathrm{H}, \mathrm{NCH}_{2}\right), 3.05-2.98$ (m, 2H, $\left.\mathrm{NCH}_{2}\right), 2.91-2.84\left(\mathrm{~m}, 2 \mathrm{H}, \mathrm{NCH}_{2}\right), 2.77-2.59\left(\mathrm{~m}, 4 \mathrm{H}, \mathrm{NCH}_{2}+\mathrm{NCH}_{2} \mathrm{CH}_{2}\right), 2.51-2.47$ (m, 2H, $\left.\mathrm{NCH}_{2}\right), 1.76-1.65\left(\mathrm{~m}, 2 \mathrm{H}, \mathrm{NCH}_{2} \mathrm{C}_{2}\right) ;{ }^{13} \mathrm{C} \mathrm{NMR}\left(76 \mathrm{MHz}, 298 \mathrm{~K}, \mathrm{D}_{2} \mathrm{O}\right) 157.51\left(\mathrm{~d},{ }^{1} \mathrm{JPC}_{\mathrm{PC}}\right.$ $=213.4$, Py $), 152.78\left(\mathrm{~d},{ }^{3} J_{\mathrm{PC}}=20.6\right.$, Py $), 138.95\left(\mathrm{~d},{ }^{3} J_{\mathrm{PC}}=11.3\right.$, Py $), 127.31\left(\mathrm{~d},{ }^{2} J_{\mathrm{PC}}=22.7, \mathrm{Py}\right)$, 125.25 (s, Py), $57.68\left(\mathrm{~s}, \mathrm{NCH}_{2}\right), 56.61\left(\mathrm{~s}, \mathrm{NCH}_{2}\right), 56.12\left(\mathrm{~s}, \mathrm{NCH}_{2}\right), 54.50\left(\mathrm{~s}, \mathrm{NCH}_{2}\right), 51.32(\mathrm{~s}$, $\left.\mathrm{NCH}_{2}\right), 49.48$ (s, $\left.\mathrm{NCH}_{2}\right), 19.64$ (s, $\left.\mathrm{NCH}_{2} \mathrm{CH}_{2}\right) ;{ }^{31} \mathrm{P} \mathrm{NMR}\left(162 \mathrm{MHz}, 298 \mathrm{~K}, \mathrm{CDCl}_{3}\right) 6.8$ (s); ESIHRMS m/z calcd. for $\left[\mathrm{C}_{24} \mathrm{H}_{38} \mathrm{~N}_{6} \mathrm{O}_{6} \mathrm{P}_{2}+\mathrm{H}\right]^{+} 569.2401$ found 569.2401; UV-vis. (Tris $\mathrm{Buffer}_{\text {(aq) }} 0.1$ M) $\lambda_{\max }\left(\varepsilon_{\max }\right) ; 229$ (4400), 286 (4600); Anal. Calcd for $\mathrm{C}_{24} \mathrm{H}_{47} \mathrm{ClN}_{6} \mathrm{O}_{10} \mathrm{P}_{2}\left(677.07 \mathrm{~g} \mathrm{~mol}^{-1}\right)$ : C, 42.26; H, 7.00; N, 12.41. Found: C, 42.58; H, 6.99; N, 12.41.

\section{Synthesis of Ln complexes $(M=L u, E u, T b, Y b)$}

\section{General Procedure:}

$\mathrm{L}_{1} \mathrm{H}_{2} .4 \mathrm{HCl}(50 \mathrm{mg}, 72.6 \mu \mathrm{mol})$ was dissolved in $\mathrm{D}_{2} \mathrm{O}(2 \mathrm{~mL})$, basified with a standard soln. of $\mathrm{NaOD}$ in $\mathrm{D}_{2} \mathrm{O}(20 \mathrm{mM})$ to $\mathrm{pD}=7$. A stock soln. of $\mathrm{LnCl}_{3} .6 \mathrm{HO}$ in $\mathrm{D}_{2} \mathrm{O}(c a .0 .5$ eq., $0.05 \mathrm{M})$ added, the $\mathrm{pD}$ equilibrated to $\mathrm{pD}=7$ and heated to 80 degrees for 18 hours. The reaction progress was monitored by ${ }^{1} \mathrm{H}$ NMR spectroscopy. A stock soln. of $\mathrm{LnCl}_{3} \cdot 6 \mathrm{H}_{2} \mathrm{O}$ in $\mathrm{D}_{2} \mathrm{O}$ (ca. 0.25 eq, $0.05 \mathrm{M}$ ) was added and the $\mathrm{pD}$ equilibrated to $\mathrm{pD}=7$, heated to $80^{\circ} \mathrm{C}$ for 18 hours and monitored by ${ }^{1} \mathrm{H}$ NMR to calculate remaining free ligand. Remaining $\mathrm{LnCl} \cdot 6 \mathrm{H}_{2} \mathrm{O}$ stock solution was added to give 1.0 eq. in total, basified to $\mathrm{pD}=7$ and heated to $80^{\circ} \mathrm{C}$ for 18 hours. The solution was acidified to $\mathrm{pD}=3.5-4.0$, the solvent was concentrated to $c a .1 \mathrm{~mL}$, precipitated by addition of acetone 
(ca. $10 \mathrm{~mL}$ ), filtered and dried. The crude reaction mixture was purified by $\mathrm{C}_{18}\left(\mathrm{H}_{2} \mathrm{O} / \mathrm{MeOH}\right.$ $100: 0 \rightarrow 80: 20)$

\section{Synthesis of $\left[\mathrm{LuL}_{1} \mathrm{D}_{2}\right] \mathrm{Cl}$}

The title compound was synthesised according to the general procedure to to give $\left[\mathrm{LuL}_{1} \mathrm{H}_{2}\right] \mathrm{Cl}$ compound as a white solid (31 mg, $41.2 \mu \mathrm{mol}, 57 \%) .{ }^{1} \mathrm{H}$ NMR (400 MHz, $\left.298 \mathrm{~K}, \mathrm{D}_{2} \mathrm{O}\right) 8.14$ (td, $\left.{ }^{3} J_{\mathrm{HH}}=7.7,{ }^{3} J_{\mathrm{HH}}=4.0,2 \mathrm{H}, \mathrm{PyH}\right), 7.85\left(\mathrm{t},{ }^{3} J_{\mathrm{HH}}=7.2,2 \mathrm{H}, \mathrm{PyH}\right), 7.70\left(\mathrm{~d},{ }^{3} J_{\mathrm{HH}}=7.8,2 \mathrm{H}, \mathrm{PyH}\right), 3.88$ $\left(\mathrm{d},{ }^{2} J_{\mathrm{HH}}=15.7,2 \mathrm{H}, \mathrm{NC} \underline{\mathrm{HH}}\right), 3.51\left(\mathrm{td},{ }^{3} J_{\mathrm{HH}}=13.2,{ }^{4} J_{\mathrm{HH}}=2.9,2 \mathrm{H}, \mathrm{NCH}_{2}\right), 3.42-3.31(\mathrm{~m}, 2 \mathrm{H}$, $\left.\mathrm{NCH}_{2}\right), 2.83\left(\mathrm{~d}, J=13.0,2 \mathrm{H}, \mathrm{NCH}_{2}\right), 2.75-2.49\left(\mathrm{~m}, 8 \mathrm{H}, \mathrm{NCH}_{2}\right), 2.03\left(\mathrm{q}, J=13.8,13.1,2 \mathrm{H}, \mathrm{NCH}_{2}\right)$, $1.83-1.87\left(\mathrm{~m}, 2 \mathrm{H}, \mathrm{NCH}_{2} \underline{\mathrm{C}}_{2}\right), 1.80-1.70\left(\mathrm{~m}, 2 \mathrm{H}, \mathrm{NCH}_{2} \underline{\mathrm{C}}_{2}\right) ;{ }^{13} \mathrm{C} \mathrm{NMR}\left(76 \mathrm{MHz}, 298 \mathrm{~K}, \mathrm{D}_{2} \mathrm{O}\right)$ $162.48\left(\mathrm{~d},{ }^{3} J_{\mathrm{PC}}=16.5, \mathrm{Py}\right), 158.63\left(\mathrm{~d},{ }^{1} J_{\mathrm{PC}}=199.6, \mathrm{Py}\right), 145.24\left(\mathrm{~d},{ }^{3} J_{\mathrm{PC}}=10.5, \mathrm{Py}\right), 129.48(\mathrm{~d}$, $\left.{ }^{2} J_{\mathrm{PC}}=19.6, \mathrm{Py}\right), 129.35\left(\mathrm{~d},{ }^{4} J_{\mathrm{PC}}=2.9, \mathrm{Py}\right), 71.72\left(\mathrm{~s}, \mathrm{NCH}_{2}\right), 62.86\left(\mathrm{~s}, \mathrm{NCH}_{2}\right), 58.47\left(\mathrm{~s}, \mathrm{NCH}_{2}\right)$,

$53.71\left(\mathrm{~s}, \mathrm{NCH}_{2}\right), 52.68\left(\mathrm{~s}, \mathrm{NCH}_{2}\right), 29.47\left(\mathrm{~s}, \mathrm{NCH}_{2}\right) ;{ }^{31} \mathrm{P} \mathrm{NMR}\left(162 \mathrm{MHz}, 298 \mathrm{~K}, \mathrm{CDCl}_{3}\right) 14.9$ (s); ESI-HRMS m/z calcd. for $\left[\mathrm{C}_{22} \mathrm{H}_{32} \mathrm{D}_{2} \mathrm{LuN}_{6} \mathrm{O}_{6} \mathrm{P}_{2} \mathrm{Cl}-\mathrm{Cl}\right]^{+} 717.1574$ found 717.1541 ; Anal. Calcd for $\mathrm{C}_{22} \mathrm{H}_{41} \mathrm{D}_{2} \mathrm{Cl}_{2} \mathrm{LuN}_{6} \mathrm{O}_{10} \mathrm{P}_{2}\left(\left[\mathrm{LuL}_{1} \mathrm{H}_{2}\right] \mathrm{Cl}+4 \mathrm{H}_{2} \mathrm{O}+1 \mathrm{HCl}\right)\left(861.45 \mathrm{~g} \mathrm{~mol}^{-1}\right): \mathrm{C}, 30.75 ; \mathrm{H}, 5.04 ; \mathrm{N}$, 9.78. Found: C, 30.59; H, 5.11; N, 9.87.

\section{Synthesis of $\left[\mathrm{EuL} \mathrm{L}_{1} \mathrm{D}\right]$}

The title compound was synthesised according to the general procedure, except that the solution was acidified to $\mathrm{pD}=5.4$, to give $\left[\mathrm{EuL}_{1} \mathrm{H}\right]$ as a white solid $(24 \mathrm{mg}, 32.0 \mu \mathrm{mol}, 44 \%) .{ }^{1} \mathrm{H} \mathrm{NMR}$ (400 MHz, D $2 \mathrm{O}) \delta 18.24$ (br. s), 10.47 (br. s), 10.45 (br. s), 10.04 (br. s), 9.10 (br. s), 4.34 (br. s), 3.01 (br. s), 0.73 (br. s), 0.05 (br. s), -1.83 (br. s), -2.26 (br. s), -2.30 (br. s), -4.22 (br. s), -5.17 (br. s), -6.30 (br. s), -9.40 (br. s), -12.99 (br. s), -14.06 (br. s); ${ }^{31} \mathrm{P}$ NMR (162 MHz, $\left.298 \mathrm{~K}, \mathrm{D}_{2} \mathrm{O}\right) 47.8$ (s); ESI-HRMS m/z calcd. for $\left[\mathrm{C}_{22} \mathrm{H}_{32} \mathrm{D}_{2} \mathrm{EuN}_{6} \mathrm{O}_{6} \mathrm{P}_{2} \mathrm{Cl}-\mathrm{Cl}\right]^{+} 695.1349$ found 695.1349; Anal. 
Calcd for $\mathrm{C}_{22} \mathrm{H}_{47} \mathrm{D}_{2} \mathrm{Cl}_{8} \mathrm{EuN}_{6} \mathrm{O}_{10} \mathrm{P}_{2}\left(\left[\mathrm{EuL}_{1} \mathrm{H}\right]+4 \mathrm{H}_{2} \mathrm{O}+8 \mathrm{HCl}\right)\left(1058.19 \mathrm{~g} \mathrm{~mol}^{-1}\right)$ : C, 25.04; H, 4.68;

N, 7.96. Found: C, 25.15; H, 4.54; N, 8.05.

\section{Synthesis of $\left[\mathrm{TbL}_{1} \mathrm{D}_{2}\right] \mathrm{Cl}$}

The title compound was synthesised according to the general procedure to to give $\left[\mathrm{TbL}_{1} \mathrm{H}_{2}\right] \mathrm{Cl}$ as a white solid (27 mg, $36.7 \mu \mathrm{mol}, 51 \%) .{ }^{1} \mathrm{H}$ NMR (400 MHz, $\left.298 \mathrm{~K}, \mathrm{D}_{2} \mathrm{O}\right) 78.02$ (br. s), 71.10 (br. s), 54.79 (br. s), 16.19 (br. s), -4.12, (br. s) -22.31 (br. s), -35.06 (br. s), -40.64 (br. s), -43.09 (br. s), -56.50 (br. s), -78.48 (br. s); ${ }^{31} \mathrm{P}$ NMR (162 MHz, $\left.298 \mathrm{~K}, \mathrm{D}_{2} \mathrm{O}\right) 168.6$ (br. s); ESI-HRMS $\mathrm{m} / \mathrm{z}$ calcd. for $\left[\mathrm{C}_{22} \mathrm{H}_{32} \mathrm{D}_{2} \mathrm{TbN}_{6} \mathrm{O}_{6} \mathrm{P}_{2} \mathrm{Cl}-\mathrm{Cl}\right]^{+} 701.1389$ found 701.1387 ; Anal. Calcd for $\mathrm{C}_{22} \mathrm{H}_{34} \mathrm{D}_{2} \mathrm{ClTbN}_{6} \mathrm{O}_{7} \mathrm{P}_{2}\left(\left[\mathrm{TbL}_{1} \mathrm{H}_{2}\right] \mathrm{Cl}+1 \mathrm{H}_{2} \mathrm{O}\right)\left(754.90 \mathrm{~g} \mathrm{~mol}^{-1}\right): \mathrm{C}, 35.10 ; \mathrm{H}, 4.82 ; \mathrm{N}, 11.16$. Found: C, 34.21; H, 5.16; N, 11.02 .

\section{Synthesis of $\left[\mathrm{YbL}_{1} \mathrm{D}_{2}\right] \mathrm{Cl}$}

The title compound was synthesised according to the general procedure to to give $\left[\mathrm{YbL}_{1} \mathrm{H}_{2}\right] \mathrm{Cl}$ as a white solid (17 mg, $22.7 \mu \mathrm{mol}, 31 \%) .{ }^{1} \mathrm{H}$ NMR (400 MHz, $\left.298 \mathrm{~K}, \mathrm{D}_{2} \mathrm{O}\right) 63.13$ (br. s), 19.21 (br. s), 18.05 (br. s), 17.82 (br. s), 17.55 (br. s), 8.08 (br. s), 7.81 (br. s), 7.63 (br. s), 0.88 (br. s), 0.24 (br. s), -5.47 (br. s), -12.71 (br. s), -13.86 (br. s), -22.44 (br. s), -29.91 (br. s), -55.25 (br. s); ${ }^{31} \mathrm{P}$ NMR (162 MHz, $\left.298 \mathrm{~K}, \mathrm{CDCl}_{3}\right) 7.5$ (br. s); ESI-HRMS m/z calcd. for $\left[\mathrm{C}_{22} \mathrm{H}_{32} \mathrm{D}_{2} \mathrm{LuN}_{6} \mathrm{O}_{6} \mathrm{P}_{2} \mathrm{Cl}\right.$ $-\mathrm{Cl}^{+} 716.1527$ found 716.1521; Anal. Calcd for $\mathrm{C}_{22} \mathrm{H}_{38} \mathrm{D}_{2} \mathrm{Cl}_{3} \mathrm{~N}_{6} \mathrm{O}_{8} \mathrm{P}_{2} \mathrm{Yb}\left(\left[\mathrm{YbL}_{1} \mathrm{H}_{2}\right] \mathrm{Cl}+2 \mathrm{H}_{2} \mathrm{O}+\right.$ $2 \mathrm{HCl})\left(859.96 \mathrm{~g} \mathrm{~mol}^{-1}\right)$ : C, 30.80; H, 4.70; N, 9.80. Found: C, 31.00; H, 5.07; N, 9.91 .

\section{Associated Content}

Supporting Information. The Supporting Information is available free of charge on the ACS Publications website at DOI: XXXXXX. ${ }^{1} \mathrm{H},{ }^{13} \mathrm{C},{ }^{31} \mathrm{P}$ NMR and ESI-HRMS spectra for ligands and corresponding $\mathrm{Ln}^{3+}$ complexes; determination experiments of the stabilities; photoluminescence spectra and calculated fittings for $\mathrm{Ln}^{3+}$ complexes. Accession Codes CCDC 
1990765,1990767 , and 1990768 contain the supplementary crystallographic data for this paper.

These data can be obtained free of charge via www.ccdc.cam.ac.uk/ data_request/cif, or by emailing data_request@ccdc.cam.ac. uk, or by contacting The Cambridge Crystallographic Data Centre, 12 Union Road, Cambridge CB2 1EZ, UK; fax: +44 1223336033.

\section{Corresponding Author}

*(R.C.K.) E-mail: knighton@unistra.fr *(L.J.C.) E-mail@ 1.charbonn@unistra.fr

\section{Author Contributions}

The manuscript was written through contributions of all authors. All authors have given approval to the final version of the manuscript.

\section{Acknowledgements}

L.J.C. acknowledges the CSC Labex of the University of Strasbourg (ANR-10-LABX-0026_CSC, UCLA project) for funding for R.C.K. and the French Ministry of National Education and Research and the France Canada Research Fund (FFCR) for L.K.S. T.T. acknowledges Région Bretagne (SAD HypoTrac) for funding for R.C.K.. R.C.K. and T.T. thank the RSC Research Fund (Grant no. RF19-0248) for the purchase of equipment. M. E. and V. M. thank the Center National de la Recherche Scientifique (CNRS) and the university of Strasbourg (LIMA UMR 7042).

\section{References}

\footnotetext{
${ }^{1}$ Marin, R.; Brunet, G.; Murugesu, M. Shining New Light on Multifunctional Lanthanide SingleMolecule Magnets. Angew. Chemie Int. Ed. 2019, DOI: 10.1002/anie.201910299
} 
${ }^{2}$ Parker, D.; Dickins, R. S.; Puschmann, H.; Crossland, C.; Howard, J. A. K. Being Excited by Lanthanide Coordination Complexes: Aqua Species, Chirality, Excited-State Chemistry, and Exchange Dynamics. Chem. Rev. 2002, 102 (6), 1977-2010.

3 Bünzli, J.-C. G. Review: Lanthanide Coordination Chemistry: From Old Concepts to Coordination Polymers. J. Coord. Chem. 2014, 67 (23-24), 3706-3733.

${ }^{4}$ Bünzli, J.-C. G.; Piguet, C. Taking Advantage of Luminescent Lanthanide Ions. Chem. Soc. Rev. 2005, 34 (12), 1048-1077.

${ }^{5}$ Klink, S. I.; Keizer, H.; van Veggel, F. C. J. M. Transition Metal Complexes as Photosensitizers for Near-Infrared Lanthanide Luminescence. Angew. Chemie Int. Ed. 2000, 39 (23), 4319-4321.

${ }^{6}$ Parker, D. Excitement in fBlock : Structure, Dynamics and Function of Nine-Coordinate Chiral Lanthanide Complexes in Aqueous Media. Chem. Soc. Rev. 2004, 33 (3), 156-165.

${ }^{7}$ Moore, E. G.; Samuel, A. P. S.; Raymond, K. N. From Antenna to Assay: Lessons Learned in Lanthanide Luminescence. Acc. Chem. Res. 2009, 42 (4), 542-552.

${ }^{8}$ Jin, G.-Q.; Ning, Y.; Geng, J.-X.; Jiang, Z.-F.; Wang, Y.; Zhang, J.-L. Joining the Journey to near Infrared (NIR) Imaging: The Emerging Role of Lanthanides in the Designing of Molecular Probes. Inorg. Chem. Front. 2020, 7 (2), 289-299.

${ }^{9}$ Dong, H.; Sun, L.-D.; Yan, C.-H. Energy Transfer in Lanthanide Upconversion Studies for Extended Optical Applications. Chem. Soc. Rev. 2015, 44 (6), 1608-1634.

10 Ward, M. D. Mechanisms of Sensitization of Lanthanide(III)-Based Luminescence in Transition Metal/Lanthanide and Anthracene/Lanthanide Dyads. Coord. Chem. Rev. 2010, 254 (21), 2634-2642. 
${ }^{11}$ Carneiro Neto, A. N.; Moura, R. T.; Malta, O. L. On the Mechanisms of Non-Radiative Energy Transfer between Lanthanide Ions: Centrosymmetric Systems. J. Lumin. 2019, 210, 342-347.

${ }^{12}$ Leonzio, M.; Melchior, A.; Faura, G.; Tolazzi, M.; Zinna, F.; Di Bari, L.; Piccinelli, F. Strongly Circularly Polarized Emission from Water-Soluble Eu(III)- and Tb(III)-Based Complexes: A Structural and Spectroscopic Study. Inorg. Chem. 2017, 56 (8), 4413-4421.

${ }^{13}$ Arrico, L.; De Rosa, C.; Di Bari, L.; Melchior, A.; Piccinelli, F. Effect of the Counterion on Circularly Polarized Luminescence of Europium(III) and Samarium(III) Complexes. Inorg. Chem. 2020, 59 (7), 5050-5062.

14 Nonat, A.; Regueiro-Figueroa, M.; Esteban-Gómez, D.; de Blas, A.; Rodríguez-Blas, T.; Platas-Iglesias, C.; Charbonnière, L. J. Definition of an Intramolecular Eu-to-Eu Energy Transfer within a Discrete [Eu2L] Complex in Solution. Chem. - A Eur. J. 2012, 18 (26), 8163-8173.

15 Zaïm, A.; Eliseeva, S. V; Guénée, L.; Nozary, H.; Petoud, S.; Piguet, C. Lanthanide-toLanthanide Energy-Transfer Processes Operating in Discrete Polynuclear Complexes: Can Trivalent Europium Be Used as a Local Structural Probe? Chem. - A Eur. J. 2014, 20 (38), $12172-$ 12182.

${ }^{16}$ Faulkner, S.; Pope, S. J. A. Lanthanide-Sensitized Lanthanide Luminescence: TerbiumSensitized Ytterbium Luminescence in a Trinuclear Complex. J. Am. Chem. Soc. 2003, 125 (35), $10526-10527$.

17 Nonat, A.; Liu, T.; Jeannin, O.; Camerel, F.; Charbonnière, L. J. Energy Transfer in Supramolecular Heteronuclear Lanthanide Dimers and Application to Fluoride Sensing in Water. Chem. - A Eur. J. 2018, 24 (15), 3784-3792. 
${ }^{18}$ Piguet, C.; Bünzli, J. C. G.; Bernardinelli, G.; Hopfgartner, G.; Williams, A. F. Self-Assembly and Photophysical Properties of Lanthanide Dinuclear Triple-Helical Complexes. J. Am. Chem. Soc. 1993, 115 (18), 8197-8206.

${ }^{19}$ Sørensen, T. J.; Faulkner, S. Multimetallic Lanthanide Complexes: Using Kinetic Control To Define Complex Multimetallic Arrays. Acc. Chem. Res. 2018, 51 (10), 2493-2501.

${ }^{20}$ Livramento, J.; Sour, A.; Borel, A.; Merbach, A.; Toth, E. A Starburst-Shaped Heterometallic Compound Incorporating Six Densely Packed Gd3+ Ions. Chemistry 2006, 12, 989-1003.

${ }^{21}$ Faulkner, S.; Natrajan, L. S.; Perry, W. S.; Sykes, D. Sensitised Luminescence in Lanthanide Containing Arrays and d-f Hybrids. Dalt. Trans. 2009, No. 20, 3890-3899.

22 Sy, M.; Esteban-Gomez, D.; Platas-Iglesias, C.; Rodriguez-Rodriguez, A.; Tripier, R.; Charbonnière, L.J. Spectroscopic properties of a family of mono- to trinuclear lanthanide complexes, Eur. J. Inorg. Chem. 2017, 2122-2129.

${ }^{23}$ Albrecht, M.; Osetska, O.; Fröhlich, R.; Bünzli, J.-C. G.; Aebischer, A.; Gumy, F.; Hamacek, J. Highly Efficient Near-IR Emitting Yb/Yb and Yb/Al Helicates. J. Am. Chem. Soc. 2007, 129 (46), 14178-14179.

${ }^{24}$ Bünzli, J.-C. G. Lighting up Cells with Lanthanide Self-Assembled Helicates. Interface Focus 2013, 3 (5), 20130032.

${ }^{25}$ Ronson, T. K.; Adams, H.; Harding, L. P.; Pope, S. J. A.; Sykes, D.; Faulkner, S.; Ward, M. D. Polynuclear Lanthanide Complexes of a Series of Bridging Ligands Containing Two Tridentate N,N',O-Donor Units: Structures and Luminescence Properties. Dalt. Trans. 2007, No. 10, 10061022. 
${ }^{26}$ Avecilla, F. ; de Blas, A. ; Bastida, R. ; Fenton, D.E. ; Mahía, J. ; Macías, A. ; Platas, C. ; Rodríguez, A.; Rodríguez-Blas, T. The template synthesis and X-ray crystal structure of the first dinuclear lanthanide(III) iminophenolate cryptate Chem. Commun. 1999, 125-126.

${ }^{27}$ Yeung, C.-T.; Yim, K.-H.; Wong, H.-Y.; Pal, R.; Lo, W.-S.; Yan, S.-C.; Yee-Man Wong, M.; Yufit, D.; Smiles, D. E.; McCormick, L. J.; Teat, S. J.; Shuh, D. K.; Wong, W.-T.; Law, G.-L. Chiral Transcription in Self-Assembled Tetrahedral Eu4L6 Chiral Cages Displaying Sizable Circularly Polarized Luminescence. Nat. Commun. 2017, 8 (1), 1128.

${ }^{28}$ Vuillamy, A.; Zebret, S.; Besnard, C.; Placide, V.; Petoud, S.; Hamacek, J. Functionalized Triptycene-Derived Tripodal Ligands: Privileged Formation of Tetranuclear Cage Assemblies with Larger Ln(III). Inorg. Chem. 2017, 56 (5), 2742-2749.

${ }^{29}$ Liu, T.; Nonat, A.; Beyler, M.; Regueiro-Figueroa, M.; Nchimi Nono, K.; Jeannin, O.; Camerel, F.; Debaene, F.; Cianférani-Sanglier, S.; Tripier, R.; Charbonnière, L. J.. Supramolecular Luminescent Lanthanide Dimers for Fluoride Sequestering and Sensing. Angew. Chemie Int. Ed. 2014, 53 (28), 7259-7263.

${ }^{30}$ Floquet, S.; Borkovec, M.; Bernardinelli, G.; Pinto, A.; Leuthold, L.-A.; Hopfgartner, G.; Imbert, D.; Bünzli, J.-C. G.; Piguet, C. Programming Heteropolymetallic Lanthanide Helicates: Thermodynamic Recognition of Different Metal Ions Along the Strands. Chem. - A Eur. J. 2004, $10(5), 1091-1105$.

${ }^{31}$ Li, X.-Z.; Zhou, L.-P.; Yan, L.-L.; Dong, Y.-M.; Bai, Z.-L.; Sun, X.-Q.; Diwu, J.; Wang, S.; Bünzli, J.-C.; Sun, Q.-F. A Supramolecular Lanthanide Separation Approach Based on Multivalent Cooperative Enhancement of Metal Ion Selectivity. Nat. Commun. 2018, 9 (1), 547. 
${ }^{32}$ Molloy, J. K.; Kotova, O.; Peacock, R. D.; Gunnlaugsson, T. Synthesis of Luminescent HomoDinuclear Cationic Lanthanide Cyclen Complexes Bearing Amide Pendant Arms through the Use of Copper Catalysed (1,3-Huisgen, CuAAC) Click Chemistry. Org. Biomol. Chem. 2012, 10 (2), $314-322$.

33 Tropiano, M.; Kenwright, A. M.; Faulkner, S. Lanthanide Complexes of AzidophenacylDO3A as New Synthons for Click Chemistry and the Synthesis of Heterometallic Lanthanide Arrays. Chem. - A Eur. J. 2015, 21 (15), 5697-5699.

34 Lewis, D. J.; Glover, P. B.; Solomons, M. C.; Pikramenou, Z. Purely Heterometallic Lanthanide(III) Macrocycles through Controlled Assembly of Disulfide Bonds for Dual Color Emission. J. Am. Chem. Soc. 2011, 133 (4), 1033-1043.

35 Lewis, D. J.; Moretta, F.; Pikramenou, Z. Controlled Assembly of Heterometallic Lanthanide(III) Macrocycles: Incorporation of Photoactive and Highly Paramagnetic Metal Centres within a Single Complex. Supramol. Chem. 2012, 24 (2), 135-142.

${ }^{36}$ Kreidt, E.; Leis, W.; Seitz, M. Direct Solid-Phase Synthesis of Molecular Heterooligonuclear Lanthanoid-Complexes. Nat. Commun. 2020, 11 (1), 1346.

${ }^{37}$ Natrajan, L. S.; Villaraza, A. J. L.; Kenwright, A. M.; Faulkner, S. Controlled Preparation of a Heterometallic Lanthanide Complex Containing Different Lanthanides in Symmetrical Binding Pockets. Chem. Commun. 2009, No. 40, 6020-6022.

${ }^{38}$ Aguilà, D.; Velasco, V.; Barrios, L. A.; González-Fabra, J.; Bo, C.; Teat, S. J.; Roubeau, O.; Aromí, G. Selective Lanthanide Distribution within a Comprehensive Series of Heterometallic [LnPr] Complexes. Inorg. Chem. 2018, 57 (14), 8429-8439. 
${ }^{39}$ Velasco, V.; Barrios, L. A.; Schütze, M.; Roubeau, O.; Luis, F.; Teat, S. J.; Aguilà, D.; Aromí, G. Controlled Heterometallic Composition in Linear Trinuclear [LnCeLn] Lanthanide Molecular Assemblies. Chem. - A Eur. J. 2019, 25 (67), 15228-15232.

${ }^{40}$ Wahsner, J.; Seitz, M. Synthesis of Inert Homo- and Heterodinuclear Rare-Earth Cryptates. Inorg. Chem. 2015, 54 (20), 9681-9683.

${ }^{41}$ Aboshyan-Sorgho, L.; Besnard, C.; Pattison, P.; Kittilstved, K. R.; Aebischer, A.; Bünzli, J.C. G.; Hauser, A.; Piguet, C. Near-Infrared $\rightarrow$ Visible Light Upconversion in a Molecular Trinuclear d-f-d Complex. Angew. Chemie Int. Ed. 2011, 50 (18), 4108-4112.

${ }^{42}$ Golesorkhi, B.; Nozary, H.; Furstenberg, A.; Piguet, C. Erbium complexes as pioneers for implementing linear light-upconversion in molecules, Materials Horizon, 2020, 7, 1279-1296.

${ }^{43}$ Charbonnière, L. J. Bringing Upconversion down to the Molecular Scale. Dalton Trans. 2018, 47 (26), 8566-8570.

${ }^{44}$ Nonat, A. M.; Charbonnière, L. J. Upconversion of Light with Molecular and Supramolecular Lanthanide Complexes. Coord. Chem. Rev. 2020, 409, 213192.

45 Aboshyan-Sorgho, L.; Cantuel, M.; Petoud, S.; Hauser, A.; Piguet, C. Optical Sensitization and Upconversion in Discrete Polynuclear Chromium-Lanthanide Complexes. Coord. Chem. Rev. 2012, 256 (15), 1644-1663.

${ }^{46}$ Mameri, S.; Charbonnière, L.J.; Ziessel, R. Lanthanide/ATP Interaction in Water Mediated by Luminescent Hemispherical-Shaped Complexes. Inorg. Chem. 2004, 43, 1819-1821.

47 Souri, N.; Tian, P.; Lecointre, A.; Lemaire, Z.; Chafaa, S.; Strub, J.-M.; Cianférani, S.; Elhabiri, M.; Platas-Iglesias, C.; Charbonnière, L. J. Step by Step Assembly of Polynuclear 
Lanthanide Complexes with a Phosphonated Bipyridine Ligand. Inorg. Chem. 2016, 55 (24), 12962-12974..

48 Souri, N.; Tian, P.; Platas-Iglesias, C.; Wong, K.-L.; Nonat, A.; Charbonnière, L. J. Upconverted Photosensitization of $\mathrm{Tb}$ Visible Emission by NIR $\mathrm{Yb}$ Excitation in Discrete Supramolecular Heteropolynuclear Complexes. J. Am. Chem. Soc. 2017, 139 (4), 1456-1459.

49 Viola-Villegas, N.; Doyle, R. P. The Coordination Chemistry of 1,4,7,10-

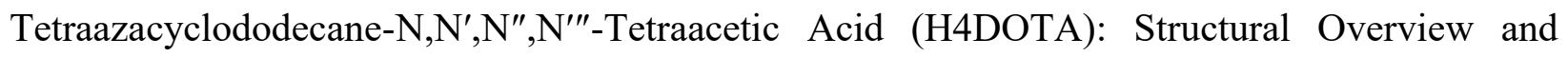
Analyses on Structure-Stability Relationships. Coord. Chem. Rev. 2009, 253 (13), 1906-1925.

${ }^{50}$ Rodríguez-Rodríguez, A.; Esteban-Gómez, D.; Tripier, R.; Tircsó, G.; Garda, Z.; Tóth, I.; de Blas, A.; Rodríguez-Blas, T.; Platas-Iglesias, C. Lanthanide(III) Complexes with a Reinforced Cyclam Ligand Show Unprecedented Kinetic Inertness. J. Am. Chem. Soc. 2014, 136 (52), 17954 17957.

${ }^{51}$ Nonat, A.; Gateau, C.; Fries, P. H.; Mazzanti, M. Lanthanide Complexes of a Picolinate Ligand Derived from 1,4,7-Triazacyclononane with Potential Application in Magnetic Resonance Imaging and Time-Resolved Luminescence Imaging. Chem. - A Eur. J. 2006, 12 (27), 7133-7150.

${ }^{52}$ Vojtíšek, P.; Cígler, P.; Kotek, J.; Rudovský, J.; Hermann, P.; Lukeš, I. Crystal Structures of Lanthanide(III) Complexes with Cyclen Derivative Bearing Three Acetate and One Methylphosphonate Pendants. Inorg. Chem. 2005, 44 (16), 5591-5599.

${ }^{53}$ Clough, T. J.; Jiang, L.; Wong, K.-L.; Long, N. J. Ligand Design Strategies to Increase Stability of Gadolinium-Based Magnetic Resonance Imaging Contrast Agents. Nat. Commun. 2019, 10 (1), 1420. 
54 Salaam, J.; Tabti, L.; Bahamyirou, S.; Lecointre, A.; Hernandez Alba, O.; Jeannin, O.; Camerel, F.; Cianférani, S.; Bentouhami, E.; Nonat, A. M.; Charbonnière, L. J. Formation of Mono- and Polynuclear Luminescent Lanthanide Complexes Based on the Coordination of Preorganized Phosphonated Pyridines. Inorg. Chem. 2018, 57 (10), 6095-6106.

${ }^{55}$ Nonat, A.; Bahamyirou, S.; Lecointre, A.; Przybilla, F.; Mély, Y.; Platas-Iglesias, C.; Camerel, F.; Jeannin, O.; Charbonnière, L. J. Molecular Upconversion in Water in Heteropolynuclear Supramolecular Tb/Yb Assemblies. J. Am. Chem. Soc. 2019, 141 (4), 1568-1576.

56 L. Prodi, M. Montalti, N. Zaccheroni, G. Pickaert, L. Charbonnière, R. Ziessel, New europium(III) complexes containing hybrid ligands with hard and soft complexation centres, New J. Chem. 2003, 27, 134-139.

${ }^{57}$ Fujita, M.; Oguro, D.; Miyazawa, M.; Oka, H.; Yamaguchi, K.; Ogura, K. Self-Assembly of Ten Molecules into Nanometre-Sized Organic Host Frameworks. Nature 1995, 378 (6556), 469_ 471.

${ }^{58}$ Olenyuk, B.; Whiteford, J. A.; Fechtenkötter, A.; Stang, P. J. Self-Assembly of Nanoscale Cuboctahedra by Coordination Chemistry. Nature 1999, 398 (6730), 796-799.

${ }^{59}$ Rodríguez-Rodríguez, A.; Regueiro-Figueroa, M.; Esteban-Gómez, D.; Tripier, R.; Tircsó, G.; Kálmán, F. K.; Bényei, A. C.; Tóth, I.; Blas, A. de; Rodríguez-Blas, T.; Platas-Iglesias, C. Complexation of Ln3+ Ions with Cyclam Dipicolinates: A Small Bridge That Makes Huge Differences in Structure, Equilibrium, and Kinetic Properties. Inorg. Chem. 2016, 55 (5), 22272239. 
${ }^{60}$ Lima, L. M. P.; Halime, Z.; Marion, R.; Camus, N.; Delgado, R.; Platas-Iglesias, C.; Tripier, R. Monopicolinate Cross-Bridged Cyclam Combining Very Fast Complexation with Very High Stability and Inertness of Its Copper(II) Complex. Inorg. Chem. 2014, 53 (10), 5269-5279.

${ }^{61}$ Weisman, G. R.; Rogers, M. E.; Wong, E. H.; Jasinski, J. P.; Paight, E. S. Cross-Bridged Cyclam. Protonation and Lithium Cation $(\mathrm{Li}+)$ Complexation in a Diamond-Lattice Cleft. J. Am. Chem. Soc. 1990, 112 (23), 8604-8605.

${ }^{62}$ Hancock, R. D.; Motekaitis, R. J.; Mashishi, J.; Cukrowski, I.; Reibenspies, J. H.; Martell, A. E. The Unusual Protonation Constants of Cyclam. A Potentiometric, Crystallographic and Molecular Mechanics Study. J. Chem. Soc. Perkin Trans. 2 1996, No. 9, 1925-1929.

${ }^{63}$ Micheloni, M.; Sabatini, A.; Paoletti, P. Solution Chemistry of Macrocycles. Part 1. Basicity Constants of 1,4,8,11-Tetra-Azacyclotetradecane, 1,4,8,12-Tetra-Azacyclopentadecane, and 1,4,8,11-Tetramethyl-1,4,8,11-Tetra-Azacyclotetradecane. J. Chem. Soc. Perkin Trans. 2 1978, No. $8,828-830$.

${ }^{64}$ Conte-Daban, A.; Beyler, M.; Tripier, R.; Hureau, C. Kinetics Are Crucial When Targeting Copper Ions to Fight Alzheimer's Disease: An Illustration with Azamacrocyclic Ligands. Chem. - A Eur. J. 2018, 24 (33), 8447-8452.

65 Suet, E.; Laouenan, A. Etude de l'interaction Ion-Ammonium Tetramines Cycliques Par Potentiometrie et Rmn a l'aide Du Programme MICMAC. Talanta 1986, 33 (9), 721-727.

${ }^{66}$ Thom, V. J.; Hosken, G. D.; Hancock, R. D. Anomalous Metal Ion Size Selectivity of Tetraaza Macrocycles. Inorg. Chem. 1985, 24 (21), 3378-3381. 
${ }^{67}$ Sun, X.; Wuest, M.; Weisman, G. R.; Wong, E. H.; Reed, D. P.; Boswell, C. A.; Motekaitis, R.; Martell, A. E.; Welch, M. J.; Anderson, C. J. Radiolabeling and In Vivo Behavior of Copper64-Labeled Cross-Bridged Cyclam Ligands. J. Med. Chem. 2002, 45 (2), 469-477.

${ }^{68}$ Abada, S.; Lecointre, A.; Christine, C.; Ehret-Sabatier, L.; Saupe, F.; Orend, G.; Brasse, D.; Ouadi, A.; Hussenet, T.; Laquerrière, P.; Elhabiri, M ; Charbonnière, L. J.. Phosphonated Chelates for Nuclear Imaging. Org. Biomol. Chem. 2014, 12 (47), 9601-9620.

${ }^{69}$ Davies, P. J.; Wainwright, K. P. 3-Hydroxypropylation of Tetraazamacrocycles and Its Effect on the Stability of Divalent Metal Complexes. Inorganica Chim. Acta 1999, 294 (1), 103-108.

${ }^{70}$ Gillet, R.; Roux, A.; Brandel, J.; Huclier-Markai, S.; Camerel, F.; Jeannin, O.; Nonat, A. M.; Charbonnière, L. J. A Bispidol Chelator with a Phosphonate Pendant Arm: Synthesis, Cu(II) Complexation, and 64Cu Labeling. Inorg. Chem. 2017, 56 (19), 11738-11752.

${ }^{71}$ Latva, M.; Takalo, H.; Mukkala, V.-M.; Matachescu, C.; Rodriguez-Ubis, J. C.; Kankare, J. Correlation between the lowest triplet state energy level of the ligand and lanthanide(III) luminescence quantum yield, Helv. Chim. Acta, 1997, 75, 149-169.

${ }^{72}$ Bünzli, J.-C. G. Lanthanide Luminescence for Biomedical Analyses and Imaging. Chem. Rev. 2010, $110(5), 2729-2755$.

73 Bünzli, J.-C. G.; Eliseeva, S. V. Lanthanide NIR Luminescence for Telecommunications, Bioanalyses and Solar Energy Conversion. J. Rare Earths 2010, 28 (6), 824-842.

${ }^{74}$ Beeby, A.; M. Clarkson, I.; S. Dickins, R.; Faulkner, S.; Parker, D.; Royle, L.; S. de Sousa, A.; A. Gareth Williams, J.; Woods, M. Non-Radiative Deactivation of the Excited States of Europium, Terbium and Ytterbium Complexes by Proximate Energy-Matched $\mathrm{OH}, \mathrm{NH}$ and $\mathrm{CH}$ 
Oscillators: An Improved Luminescence Method for Establishing Solution Hydration States. J. Chem. Soc. Perkin Trans. 2 1999, No. 3, 493-504.

${ }^{75}$ Horrocks, W. D.; Sudnick, D. R. Lanthanide Ion Luminescence Probes of the Structure of Biological Macromolecules. Acc. Chem. Res. 1981, 14 (12), 384-392.

76 Ishida, H.; Tobita, S.; Hasegawa, Y.; Katoh, R.; Nozaki, K. Recent Advances in Instrumentation for Absolute Emission Quantum Yield Measurements. Coord. Chem. Rev. 2010, 254 (21), 2449-2458.

${ }^{77}$ Olmsted, J. Calorimetric Determinations of Absolute Fluorescence Quantum Yields. J. Phys. Chem. 1979, 83 (20), 2581-2584.

78 Benson, R. C.; Kues, H. A. Fluorescence Properties of Indocyanine Green as Related to Angiography. Phys. Med. Biol. 1978, 23 (1), 159-163.

${ }^{79}$ Guanci, C.; Giovenzana, G.; Lattuada, L.; Platas-Iglesias, C.; Charbonnière, L.J., AMPED: a new platform for picolinate based luminescent lanthanide chelates, Dalton Trans., 2015, 44, 76547661.

${ }^{80}$ Walton, J. W.; Carr, R.; Evans, N. H.; Funk, A. M.; Kenwright, A. M.; Parker, D.; Yufit, D. S.; Botta, M.; De Pinto, S.; Wong, K.-L. Isostructural Series of Nine-Coordinate Chiral Lanthanide Complexes Based on Triazacyclononane Inorg. Chem., 2012, 51, 8042-8056.

${ }^{81}$ Werts, M.H.V.; Jukes, R.T.F.; Verhoeven, J.W., The emission spectrum and the radiative lifetime of $\mathrm{Eu}^{3+}$ in luminescent lanthanide complexes, Phys. Chem. Chem. Phys. 2002, 4, 15421548. 
${ }^{82}$ Nocton, G.; Nonat, A.; Gateau, C.; Mazzanti, M. Water Stability and Luminescence of Lanthanide Complexes of Tripodal Ligands Derived from 1,4,7-Triazacyclononane: Pyridinecarboxamide versus Pyridinecarboxylate Donors. Helv. Chim. Acta 2009, 92 (11), 22572273.

${ }^{83}$ Asano-Someda, M.; Kaizu, Y. Hot Bands of (f, F*) Emission from Ytterbium(III) Porphyrins in Solution. J. Photochem. Photobiol. A Chem. 2001, 139 (2), 161-165.

84 Ziessel, R.F.; Ulrich, G.; Charbonnière, L.J.; Imbert, D.; Scopelliti, R.; Bünzli, J.-C.G. Chem. NIR lanthanide luminescence by energy transfer from appended terpyridine-boradiazaindacene dyes, Eur. J. Chem., 2006, 12, 5060-5067.

${ }^{85}$ Dickins, R.S.; Parker, D.; Bruce, J.I.; Tozer, D.J., Correlation of optical and NMR spectral information with coordination variation for axially symmetric macrocyclic $\mathrm{Eu}(\mathrm{III})$ and $\mathrm{Yb}(\mathrm{III})$ complexes: axial donor polarizability determines ligand field and cation donor preference Dalton Trans., 2003, 1264-1271.

${ }^{86}$ Mendy, J.; Thy Bui, A.; Roux, A.; Mulatier, J.-C.; Curton, D.; Duperray, A.; Grichine, A.; Guyot, Y.; Brasselet, S.; Riobé, F.; Andraud, C.; Le Guennic, B.; Patinec, P.; Tripier, R.; Beyler, M.; Maury, O. Cationic Biphotonic Lanthanide Luminescent Bioprobes Based on Functionalized Cross-Bridged Cyclam Macrocycles. ChemPhysChem 2020, 21 (10), 1036-1043.

${ }^{87}$ The titration was also followed by ${ }^{31} \mathrm{P}$ NMR but gave rise to broad resonances that were unable to be followed after 0.5 equivalents (See Supplementary Information, Section 6.1.3) 
${ }^{88}$ Gampp, H.; Maeder, M.; Meyer, C. J.; Zuberbu“hler, A. D. Calculation of Equilibrium Constants from Multiwavelength Spectroscopic Data-II132, 95.: Specfit: Two User-Friendly Programs in Basic and Standard Fortran 77. Talanta 1985, 32 (4), 257-264.

${ }^{89}$ Gampp, H.; Maeder, M.; Meyer, C. J.; Zuberbühler, A. D. Calculation of Equilibrium Constants from Multiwavelength Spectroscopic Data-III: Model-Free Analysis of Spectrophotometric and ESR Titrations. Talanta 1985, 32 (12), 1133-1139.

${ }^{90}$ Molecular Fluorescence: Principles and Applications, 2nd ed.; Valeur, B., Berberan-Santos, M. N., Eds.; Wiley-VCH: Weinheim, 2013.

${ }^{91}$ Prodi, L.; Montalti, M.; Zaccheroni, N. ; Pickaert, G. ; Charbonnière, L.J.; Ziessel, R. New europium(III) complexes containing hybrid ligands with hard and soft complexation centres, New J. Chem. 2003, 27, 134-139.

92 Chartres, J. D.; Lindoy, L. F.; Meehan, G. V. New Heterotopic, Linked Macrocyclic Systems Derived from Selectively Protected Macrocycles. Tetrahedron 2006, 62 (17), 4173-4187.

${ }^{93}$ Wong, E. H.; Weisman, G. R.; Hill, D. C.; Reed, D. P.; Rogers, M. E.; Condon, J. S.; Fagan, M. A.; Calabrese, J. C.; Lam, K.-C.; Guzei, I. A.; Rhengold, A. L. Synthesis and Characterization of Cross-Bridged Cyclams and Pendant-Armed Derivatives and Structural Studies of Their Copper(II) Complexes. J. Am. Chem. Soc. 2000, 122 (43), 10561-10572.

${ }^{94}$ Méthodes d'Analyses Complexométriques avec les Titriplex ${ }^{\circledR}$, Ed. Merck, Darmstadt.

95 Gans, P.; O’Sullivan, B. GLEE, a New Computer Program for Glass Electrode Calibration. Talanta 2000, 51 (1), 33-37. 
${ }^{96}$ Gans, P.; Sabatini, A.; Vacca, A. Investigation of Equilibria in Solution. Determination of Equilibrium Constants with the HYPERQUAD Suite of Programs. Talanta 1996, 43 (10), 17391753.

97 Gampp, H.; Maeder, M.; Meyer, C. J.; Zuberbühler, A. D. Calculation of Equilibrium Constants from Multiwavelength Spectroscopic Data-I: Mathematical Considerations. Talanta 1985, $32(2), 95-101$.

${ }^{98}$ P. Gans, Data Fitting in the Chemical Sciences, John Wiley \& Sons, Chichester, 1992.

${ }^{99}$ Marquardt, D. W. An Algorithm for Least-Squares Estimation of Nonlinear Parameters. $J$. Soc. Ind. Appl. Math. 1963, 11 (2), 431-441.

${ }^{100}$ Maeder, M.; Zuberbuehler, A. D. Nonlinear Least-Squares Fitting of Multivariate Absorption Data. Anal. Chem. 1990, 62 (20), 2220-2224.

\section{Table of Contents}




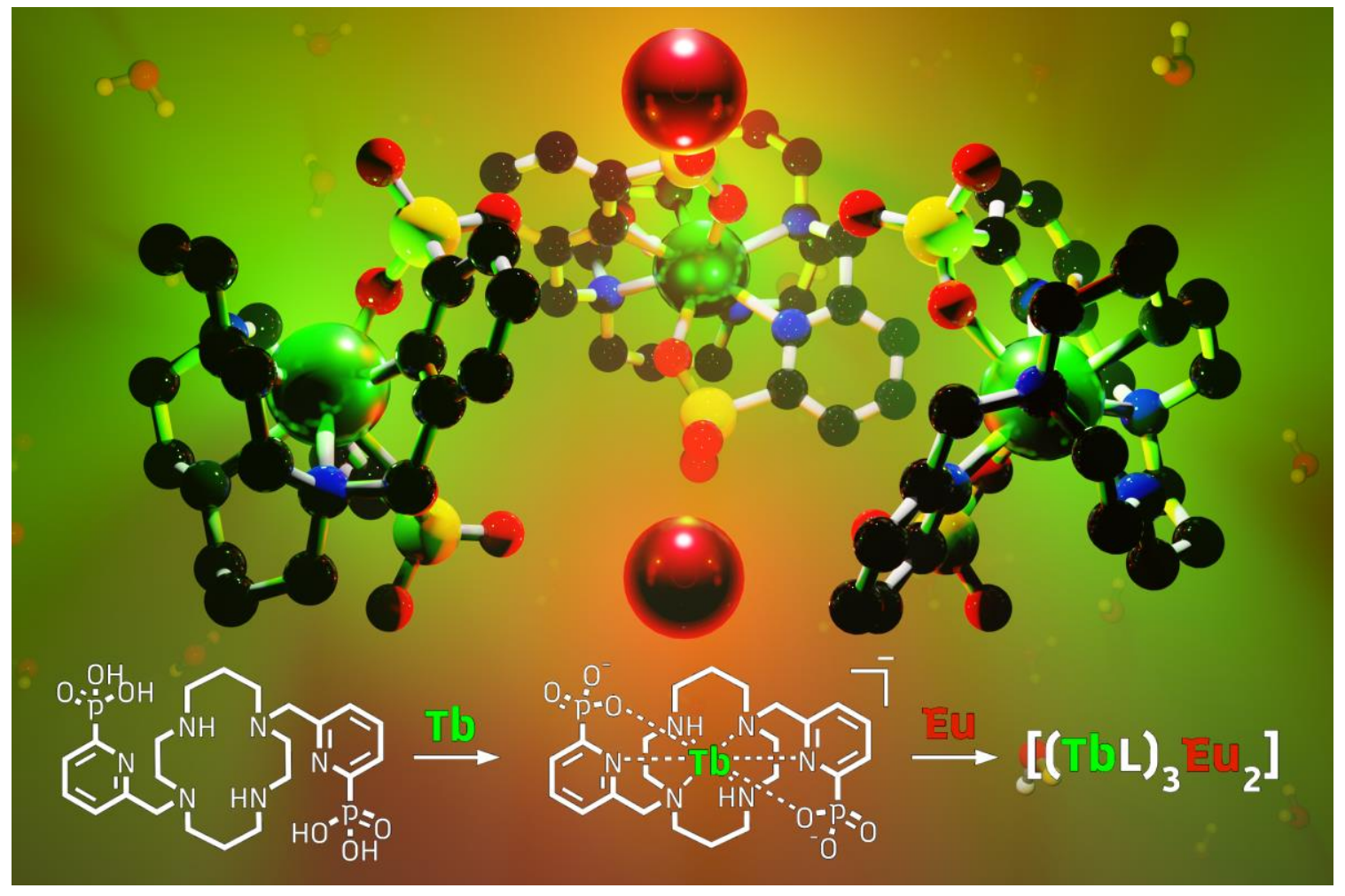

A series of lanthanide complexes have been prepared with the general formula $\left[\mathrm{LnL}_{1} \mathrm{D}_{\mathrm{x}}\right] \mathrm{Cl}_{\mathrm{x}-1}\left(\mathrm{Ln}^{3+}\right.$ $\left.=\mathrm{Lu} \mathrm{Tb}, \mathrm{Yb} ; \mathrm{x}=2 ; \mathrm{Ln}^{3+}=\mathrm{Eu}, \mathrm{x}=1\right)$. The solution, structural, potentiometric and photophysical properties of these complexes have been investigated. Spectrophotometric titrations of the isolated $\left[\mathrm{TbL}_{1}\right]^{-}$complex by $\mathrm{EuCl}_{3}$ salts demonstrated the formation of (hetero)polymetallic species in aqueous solution $\left(\mathrm{H}_{2} \mathrm{O}, \mathrm{pH}=7\right)$, displaying efficient $(>90 \%)$ energy transfer. 
